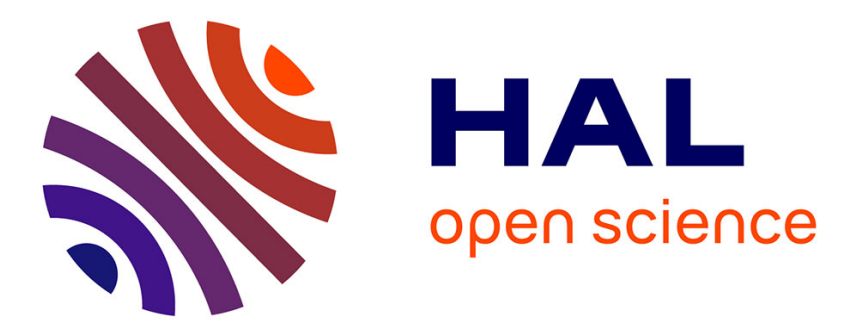

\title{
Le littoral, espace de médiations - Cultes des monts Sengen, Asama, Aomine et systèmes de représentations chez les gens de mer de la côte orientale de la péninsule de Kii
}

Anne Bouchy

\section{To cite this version:}

Anne Bouchy. Le littoral, espace de médiations - Cultes des monts Sengen, Asama, Aomine et systèmes de représentations chez les gens de mer de la côte orientale de la péninsule de Kii. Cahiers d'ExtrêmeAsie, 1996, no. 9, p. 255-298. 10.3406/asie.1996.1120 . halshs-03134239

\section{HAL Id: halshs-03134239 \\ https://shs.hal.science/halshs-03134239}

Submitted on 8 Feb 2021

HAL is a multi-disciplinary open access archive for the deposit and dissemination of scientific research documents, whether they are published or not. The documents may come from teaching and research institutions in France or abroad, or from public or private research centers.
L'archive ouverte pluridisciplinaire HAL, est destinée au dépôt et à la diffusion de documents scientifiques de niveau recherche, publiés ou non, émanant des établissements d'enseignement et de recherche français ou étrangers, des laboratoires publics ou privés. 


\section{Le littoral, espace de médiations - Cultes des monts Sengen,} Asama, Aomine et systèmes de représentations chez les gens de mer de la côte orientale de la péninsule de Kii

\section{Anne Bouchy}

\section{Citer ce document / Cite this document :}

Bouchy Anne. Le littoral, espace de médiations - Cultes des monts Sengen, Asama, Aomine et systèmes de représentations chez les gens de mer de la côte orientale de la péninsule de Kii. In: Cahiers d'Extrême-Asie, vol. 9, 1996. Mémorial Anna Seidel. Religions traditionnelles d'Asie orientale. Tome II. pp. 255-298;

doi : https://doi.org/10.3406/asie.1996.1120

https://www.persee.fr/doc/asie_0766-1177_1996_num_9_1_1120

Fichier pdf généré le 06/02/2019 


\begin{abstract}
The first part of the survey deals with the festival in honor of the sea- and mountain-god Sengen in three small harbors of Mie prefecture. Hōza and Isozaki are fishing harbors but Azena is a place where women-divers collect shells and sea-weeds. Even today, in this region, the eastern coastal range of Kii peninsula, these festivals share much in common: purification rites, formulation, the communities' banquets and festivities open to all, and the worship of Sengen. The main worship takes place on heights devoted to Sengen where ornate bonden poles are planted. At the same time, these sacred heights play the role of sea-marks helping the sailors and of a kind of relay or replica of the Japanese sacred mountains. The worship practiced there goes back to archaic marine religious traditions but has been very conspicuously influenced by the kō pilgrims' sodalities which have been controlled by the mountain-ascetics of Shugendō for a long period. Taboos of Shugendō as women prohibiting could have been found somewhat compatible with sea-societies haunted by the fear of defilements. These special features of the cult of Sengen, unified by the Shugendō of Mount Fuji, of which Sengen is the God, and confined to a clearly defined coastal area, pose the wider problem of the convergence of maritime and mountain religious spheres.

In order to better appreciate the influence exerted by the assimilation of sea-related worship by a unifying mountain-worship and of the following partial occlusion of what constitutes the specificity of the sea-faring peoples, the second part of the survey is extended to cover two famous mountain-temples of the hinterland of the eastern Kii seaside. The first is the oku no in of the Kongōshōji on Mount Asama in the Ise country. Its takemairi is a local cult for the dead which can be seen as a duplicate of funerary practices related to a marine netherworld still ongoing during the New Year period on the not so distant beaches of the Kii seaside. The second is the Shōfukuji of Mount Aomine in the Shima country. Two tales about its foundation are extant. Both can be understood as referring to the relocation of a seadeity (Ōsatsu Kannon) who was transformed into a mountain-deity. Her brilliance shines far away on the sea and she is still venerated by the sea-faring people spanning the whole of Japan's Pacific coast. This attempt to relocate the worship of Sengen inside the history of the systems of representation of the sea-faring people is only an element of a survey which should cover all the coastal regions and which could also focus on a complex of symbols as suggestive as Mount Fuji itself We can observe a paradigm shift in a seaside which is first seen as a departure point toward a netherworld beyond the sea or as a refuge for gods or men from the outside world, and then is considered to be a line of reefs and heights being the forefront of the land (riku) used for mountain worship. This shift shows a process of "sedentarisation" with ideological intent. The coastal populations, heirs of the "nomads of the sea", when redefining their vision of the world, visible and invisible, see the occlusion of their genuine world, the sea.

Deciphering the process of occluding the world of the sea gives a new approach to the vision that the Japanese society has of itself and transmits to others, its statements both of identity and of otherness.
\end{abstract}




\title{
LE LITTORAL, ESPACE DE MÉDIATIONS
}

\author{
CULTES DES MONTS SENGEN, ASAMA, AOMINE ET SYSTĖMES DE REPRÉSENTATIONS \\ CHEZ LES GENS DE MER DE LA CÔTE ORIENTALE DE LA PÉNINSULE DE KII -
}

\author{
Anne BOUCHY
}

The first part of the survey deals with the festival in honor of the sea- and mountain-god Sengen in three small harbors of Mie prefecture. Hōza and Isozaki are fishing harbors but Azena is a place where women-divers collect shells and sea-weeds. Even today, in this region, the eastern coastal range of Kii peninsula, these festivals share much in common : purification rites, formulation, the communities' banquets and festivities open to all, and the worship of Sengen. The main worship takes place on heights devoted to Sengen where ornate bonden poles are planted. At the same time, these sacred heights play the role of sea-marks helping the sailors and of a kind of relay or replica of the Japanese sacred mountains. The worship practiced there goes back to archaic marine religious traditions but has been very conspicuously influenced by the kō pilgrims' sodalities which have been controlled by the mountain-ascetics of Shugendo for a long period. Taboos of Shugendō as women prohibiting could have been found somewhat compatible with sea-societies haunted by the fear of defilements. These special features of the cult of Sengen, unified by the Shugendo of Mount Fuji, of which Sengen is the God, and confined to a clearly defined coastal area, pose the wider problem of the convergence of maritime and mountain religious spheres.

In order to better appreciate the influence exerted by the assimilation of sea-related worship by a unifying mountain-worship and of the following partial occlusion of what constitutes the specificity of the sea-faring peoples, the second part of the survey is extended to cover two famous mountain-temples of the hinterland of the eastern Kii seaside. The first is the oku no in of the Kongōshoji on Mount Asama in the Ise country. Its takemairi is a local cult for the dead which can be seen as a duplicate of funerary practices related to a marine netherworld still ongoing during the New Year period on the not so distant beaches of the Kii seaside. The second is the Shofukuji of Mount Aomine in the Shima country. Two tales about its foundation are extant. Both can be understood as referring to the relocation of a sea-deity (Ōsatsu Kannon) who was transformed into a mountain-deity. Her brilliance shines far away on the sea and she is still venerated by the sea-faring people

Cuhiers d'Extrême-Asie 9 (1996-1997) : 255-298. 
spanning the whole of Japan's Pacific coast.

This attempt to relocate the worship of Sengen inside the history of the systems of representation of the sea-faring people is only an element of a survey which should cover all the coastal regions and which could also focus on a complex of symbols as suggestive as Mount Fuji itself. We can observe a paradigm shift in a seaside which is first seen as a departure point toward a netherworld beyond the sea or as a refuge for gods or men from the outside world, and then is considered to be a line of reefs and heights being the forefront of the land (riku) used for mountain worship. This shift shows a process of "sedentarisation" with ideological intent. The coastal populations, heirs of the "nomads of the sea", when redefining their vision of the world, visible and invisible, see the occlusion of their genuine world, the sea.

Deciphering the process of occluding the world of the sea gives a new approach to the vision that the Japanese society has of itself and transmits to others, its statements both of identity and of otherness.

... Ise, pays du vent des dieux, ce pays où viennent déferler sans fin les vagues du monde immuable - tokoyo - ...

Nihon shoki, Suinin, 25. 3. 10

... montée sur une grosse tortue, et accompagnée de Tamayori hime, sa sœur cadette,

Toyotama hime, illuminant la mer, arriva (sur la grève).

Nihon shoki, Age des dieux 2, 10

Ensuite le dieu Sukunabikona

se rendit au cap de Kumano,

et de là il partit pour le monde immuable - tokoyo -

Nihon shoki, Age des dieux 1,7

\section{Bambous en fête et ablutions en mer}

En haut de la longue côte orientale de la péninsule de Kii 紀伊半島 $(140 \mathrm{~km})$, qui s'étend du cap Shio 潮岬 et Kushimoto 串本 au sud à la presqu'île de Shima 志摩半 島, au nord-est, une anse allongée s'ouvre sur la mer de Kumano (Kumano nada 熊 野灘), seuil de l'océan Pacifique; au fond : le petit port de pêche de Hōza 方座 (dépt. de Mie 三重, Nantōchō 南島町). Dans la chaleur de juillet les rues étroites résonnent des chants de la fête de Sengen 浅間 : 
Montagne de notre amour, mont Fuji, montagne aimée des hommes.

Le mont Sengen, avec quels mots le vénérerons-nous? Namu ya Sengen daibosatsu! (Hommage au grand bodhisattva Sengen)

Pour le mont Sengen, il faut danser nous dit-on! Eh bien ! dansons et montrons nos pas de danse !...

En pleine mer, dans la baie, au large, recevoir l" "aspersion", n'est-ce pas le signe de la pêche au thon !...

Entre les lanternes, les guirlandes multicolores et les lacis aériens de fils électriques et téléphoniques, circulent deux grosses perches de bambou - bonden 梵天 -, l'une de vingt et l'autre de quinze mètres de haut, dont les cimes feuillues sont décorées respectivement de cent vingt et de quatre-vingt-dix éventails blancs à rond rouge,.et les hampes, de touffes de papier blanc. Chacune d'elles est véhiculée par un groupe de dix jeunes gens, torses et jambes nus, portant serre-tête et larges ceintures de coton blanc, qui s'époumonent à chanter, vont de maison en maison en dansant, tout en s'efforçant de maintenir parfaitement droites les perches de bambou qu'ils tirent ou retiennent par quatre cordes de chanvre fixées en leur milieu. Le tour de la localité terminé, les deux groupes de porteurs, toujours en chantant, prennent d'assaut la montagne de Sengen, qui surplombe de son cône boisé l'anse allongée de Hōza. Ils rivalisent de vitesse et d'adresse pour gravir le plus vite possible la pente sans faire perdre aux bambous leur verticalité. Cette compétition s'achève au sommet, devant l'oratoire de Sengen, dieu de la montagne et de la bonne pêche, où, après la récitation d'invocations, les deux perches de bambou sont fixées au grand pin qui domine la baie (Photo 1). Durant toute l'année à venir, deux des porteurs auront la charge de surveiller que les bambous de Sengen restent droits et bien visibles des bateaux rentrant au poit. Tous redescendent pour partager un banquet qui clôt la retraite et la fête de Sengen. A Hōza, la fête de Sengen est célébrée le $28^{e}$ jour du $5^{\mathrm{e}}$ mois lunaire. Cette année-là (1982) la fête tombait le 18 iuillet. Depuis le 14, deux des porteurs et cinq des membres réguliers de la confrérie de Sengen (maîtres de maison) avaient pratiqué chaque jour vers dix-sept heures, au nom de toute la communauté, la purification (kori 垢離) qui consiste à s'immerger soixantequatre fois dans la mer au pied de la montagne de Sengen. Cette purification s'achève par la récitation des invocations rituelles dans la "demeure de Sengen" (Sengen yado 浅間宿) où tous avaient passé la nuit du 17.

Le 20 juillet ( $30^{\mathrm{e}}$ jour du $5^{\mathrm{e}}$ mois lunaire), à quelque soixante-dix kilomètres plus au sud sur cette même côte, comme tous les ans, les habitants du port d'Isozaki 磯崎 (dépt. de Mie, Kumano) célèbrent eux aussi la fête de Sengen. Ici pas de danses ni de manifestations bruyantes. Depuis six jours les membres volontaires de la confrérie de Sengen, tous des pêcheurs maîtres de maison, se sont relayés pour accomplir les ablutions rituelles et réciter les invocations devant l'image de Sengen ōkami 浅間大神 suspendue pour l'occasion, comme chaque année, dans le tokonoma 
床の間 de la maison Kawaguchi 川口, ancien shōya 庄屋 et “demeure de Sengen”, située sur le port, à deux pas de la coopérative et du sanctuaire de la localité (Photos

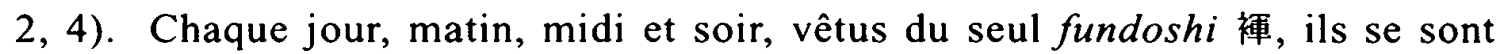
immergés dans le port, face à la montagne de Sengen, quatre fois pour la communauté, huit fois pour chaque demande personnelle, en criant "Yuhi !". Dans la matinée de ce 20 juillet, quatre de ces gyōnin 行人 - pratiquants de l'ascèse - ont fait cinquante ablutions, précédées et closes par la récitation de huit "nenbutsu 念仏 invocations - de Sengen" et treize nenbutsu d'Amida :

Gokinen gokitō gokimyō chōrai 御祈念御祈䘠御歸命頂礼

Sengen Sengen dokkoi

浅間浅間どっこい

Sangi sangi rokkon sangi

傤悔傤悔六根懴悔

Oyama ni hatsu dai Kongō dōji

お山に八大金剛童子

(Oshime ni hatsu dai Kongō dōji ) (A notre étole les huit grands Kongō dōji : variante) おしめに八大金㴊童子

Namu Sengen dai bosatsu...

南無浅間大菩薩

(transcription reproduisant le texte local avec ses particularités et quelques altérations de prononciation)

Plantés sur le port à l'endroit où les hommes font les ablutions, se dressent les bambous de Sengen aux cimes feuillues et parées de touffes blanches de gohei 御幣 qui ont été confectionnés la veille par les soins de tous : deux "grands bambous" $(9 \mathrm{~m})$, deux "bonden" $(8 \mathrm{~m})$, six "bambous de purification" $(3 \mathrm{~m})$ et cinquante "petits bambous" (Photo 3). Après un repas maigre, composé de riz aux fèves et de légumes (fournis par l'ensemble des familles et apportés par les femmes), préparé et partagé, comme tous ceux des jours précédents, par les membres de la confrérie dans la "demeure de Sengen", a lieu le tour des maisons avec les "bambous de purification". Chaque demeure est "balayée" par le bambou introduit par la porte ou la fenêtre par son porteur qui reste à l'extérieur et récite les formules de purification. Pendant ce temps les enfants reçoivent un petit bambou qu'ils vont tremper dans l'eau pour le purifier, comme cela a été fait pour tous les autres, et attendent le retour des gyōnin, cette année particulièrement peu nombreux. Toutes les maisons ayant été visitées, le petit groupe se reforme sur le port. Les membres de la confrérie, vêtus de l'habit blanc portant au dos l'inscription de Sengen ōkami, le grand chapelet en travers de la poitrine, s'emparent alors des deux bonden et des deux "grands bambous". Puis, suivis des enfants et d'hommes de la localité portant le reste des bambous, ils prennent le chemin de la montagne de Sengen qui surplombe le port d'une centaine de mètres. Au bout d'une demi-heure de marche rythmée par les conques, le cortège s'arrête au sommet devant l'oratoire de Sengen, qui abrite une statue de pierre de Dainichi nyorai 大日如來 considéré comme “dieu 
de la montagne" et protecteur des pêcheurs. Tous les gohei sont enlevés des petits bambous, fixés aux deux "grands bambous" en un ensemble nommé "montagne", et le tout est hissé le plus haut possible avec les deux bonden sur le plus grand arbre du lieu qui a remplacé le pin séculaire de Sengen disparu : cet emblème de Sengen est l'amer sur lequel les bateaux ajustent leur direction pour le retour au port. Après un bref service accompli par le moine du temple d'Isozaki, tous redescendent. En cours de route, pour marquer la fin de l" ascèse", les hommes boivent quelques gouttes de sake versé dans des feuilles d'araliacée, passent s'incliner devant le sanctuaire de la localité et terminent la journée par un banquet de fête et de "fin d'abstinence" (shojjin otoshi 精進落し).

Un mois plus tôt, le 28 juin - pour le $28^{\mathrm{e}}$ jour du $5^{\mathrm{e}}$ mois lunaire - à l'extrémité nord de cette même côte, dans la presqu'île de Shima, terroir des plongeuses qui collectent algues et ormeaux, la plage d'Azena 畔名 (dépt. de Mie, Daiōchō 大王町) est elle aussi sous le signe de Sengen. Visage protégé par un vaste chapeau de paille sous le soleil de ce début d'après-midi, toutes les femmes de la localité, des plongeuses, sont assises sur la plage, face au large, des deux côtés d'une haute bannière aux caractères de "Fuji Sengen ōkami sha" 富士浅間大神社 et d'une forêt de petits bambous plantés par elles dans le sable clair. Avant de s'asseoir, chacune d'elles est allée lancer dans la mer une offrande de quelques poignées de grains de riz apportés dans une mesure carrée. L'arrivée des hommes, portant le grand bonden à cime feuillue qu'ils viennent dresser au cœur de la touffe de bambous, est accueillie par le son d'une conque et les frappements d'un tambour que deux d'entre elles font résonner. Les hommes, ceux des membres de la confrérie de Fuji Sengen qui ont déjà fait plus de deux fois l'ascension du mont Fuji, se dirigent ensuite vers le rivage pour le sōgori 総垢離 - la "purification en commun" - : sept séries d'immersions dans la mer (Photo 5). Après chaque série d'immersions, ils viennent déposer une poignée de cailloux pris au fond de l'eau devant l'autel de Sengen placé au centre des bambous. Conque et tambour rythment leurs allées et venues. Une fois les ablutions des hommes achevées, chaque femme repart avec un petit bambou qui restera fixé à l'entrée de la maison jusqu'à l'année suivante pour la protéger. Pendant ce temps les hommes vont dresser le bonden à la cime du grand pin qui jouxte l'oratoire de Sengen, au bout de la plage, dans le prolongement de la ligne rocheuse qui délimite celle-ci (Photo 6). Dans l'oratoire, sont vénérés Dainichi et En no gyōja 役行者. Dans la soirée, après une dernière série d'ablutions, les hommes parcourent la localité en chantant les nombreux couplets du pèlerinage au Fuji :

Est-ce le vent d'est ou celui du sud qui souffle soyo - si doux - ? vers le port de Yoshida, soyo, soyo - tout doux, tout doux - !...

Sur le mont Fuji pleut le crachin, chez nous, il pleut du riz blanc !...

Et la fête de Sengen s'achève par un banquet qui se tient chez l'un des membres de la confrérie. 


\section{Une ligne côtière sous le signe de Sengen}

C'est entre 1979 et 1982 au cours d'une série d'enquêtes sur le territoire de la ville de Kumano' que mon attention fut attirée par le problème du culte de Sengen sur cette partie du littoral de la péninsule de Kii : dans tous les petits ports de pêche de la ville de Kumano existent une montagne, un oratoire, une fête de Sengen et une confrérie (Sengen kō 浅間講 ou Fuji kō 富士講) qui en a la charge. Poussant mes investigations plus loin vers le sud et vers le nord de cette côte, je m'aperçus qu'il en était de même partout : dans quasiment toutes les localités côtières dont la majorité de la population vit de la pêche, se retrouve cette même "montagne de Sengen"; existe ou a existé un groupe d'hommes pratiquant la purification de Sengen. Mais, alors que ce culte continue à l'intérieur de la baie d'Ise, il disparaît brusquement du paysage religieux de la côte de Wakayama à partir de Kushimoto et du cap Shio.

En outre, dans les localités où la pêche a été l'activité principale mais ne l'est plus, le culte de Sengen a disparu à peu près en même temps que la pêche, à partir des années Taishō 大正 (1912-25). Seule la montagne de Sengen et la mémoire des anciens en témoignent encore. C'est le cas en particulier entre Kushimoto et Kumano.

Pour en savoir davantage, je commençai alors une exploration systématique des localités situées en bordure de tout ce littoral. Dans beaucoup de cas les documents écrits étaient minces : incendies et raz de marée étaient passés dans toutes les criques. Mais ce qui subsiste de registres plus ou moins anciens, de notes manuscrites sur l'histoire de l'oratoire, de feuillets de chants et d'invocations, d'itinéraires du pélerinage, associé aux informations recélées par les statues des oratoires, les peintures sur rouleaux, les estampes des confréries et surtout les pratiques et les récits de tous ceux qui entretiennent encore aujourd'hui le culte de Sengen ou sont les héritiers des souvenirs des générations précédentes me permit de reconstituer progressivement le tableau général des réalités et des problèmes que pose l'existence du culte de Sengen le long de cette ligne côtière.

Au-delà des variations locales actuelles de cette tradition, souvent caractérisées par la disparition, et corrélativement par le développement, d'un ou de plusieurs éléments de l'ensemble "culte de Sengen", ce qui frappe dès l'abord, c'est l'unité fondamentale du phénomène, tant dans ses aspects matériels, topographiques, que dans ses dimensions religieuse, sociale et historique.

Sengen est vénéré au sommet d'une éminence (terre interdite aux femmes, autrefois du moins), d'une centaine de mètres environ, surplombant le port (ou, dans certains cas où le relief est relativement plat, sur un point marquant de l'anse) qui est toujours dans une position topographique remarquable par rapport à l'embarcadère et la localité, et sert d'amer pour les bateaux au large ou rentrant au port (Photo 7).

1 Ville de Kumano : ensemble de sept communes de montagnards-agriculteurs et de pêcheurs ayant acquis le statut de ville par regroupement administratif en 1954. Voir A. Bouchy $1983 \mathrm{a}, \mathrm{b}$. 
L'oratoire de Sengen, parfois une simple pierre, abrite dans la plupart des cas une statue de pierre du buddha Dainichi datant de l'époque d'Edo, beaucoup plus rarement celle de Konohana no sakuya hime 木花之開耶姫, figure féminine shinto de la divinité du mont Fuji; souvent lui est associée celle d'En no gyōja, fondateur du shugendō, parfois celle du buddha Yakushi. Cet oratoire est le plus souvent appelé "Sengen san", mais aussi, et cela conjointement ou non, "Dainichi sama", "yama no kami" - dieu de la montagne -, "Ofuji san", "Takagami sama" - dieu "élevé" (puissant) -. Parfois "Konohana sakuya hime san" est utilisé pour désigner le buddha Dainichi (Photo 10).

Sengen est considéré d'une façon unanime comme le dieu de la montagne et de la mer, protecteur des bateaux et des équipages en mer, mais aussi de toute la communauté qui vit à son pied (généralement, il existe cependant dans ces mêmes localités un dieu de la montagne au sens propre et distinct de Sengen, ainsi que de nombreuses autres divinités de la mer); dispensateur de bonne pêche, protecteur des enfants lorsqu'ils jouent dans l'eau et sont à la merci des puissances dangereuses de celle-ci; divinité de la longévité, du feu; divinité féminine qui "doit être vénérée sur une hauteur" où ne vont pas les femmes. On l'appelle aussi "ryōgami sama" 画 神様 - le “dieu double" -, car dans son culte sont mêlés des éléments bouddhiques et shintō, l'encens et le sake, les services des moines et ceux des prêtres.

Son culte est entretenu par une confrérie (ou plusieurs dans une même localité si celle-ci est importante; dans ce cas les différentes fonctions sont assumées par roulement entre les confréries) nommée Sengen kō, ou Fuji kō, Dainichi kō, kori 䛸 離 (ou shojin 精進) nakama 仲間 - les compagnons de purification -, qui anciennement regroupait tous les hommes de la localité, et actuellement, selon les lieux, uniquement ceux qui souhaitent en faire partie ou uniquement les maîtres de maison. Cette confrérie a un responsable (kōmoto 講元), généralement le maître de maison d'une famille influente et aisée, qui peut être le descendant de l'introducteur du culte dans la communauté; un "guide" (sendatsu 先達) pour les pèlerinages au mont Fuji et au mont Ōmine 大峰山, qui peut être ce même responsable ou non; elle associe parfois à ses activités le groupe des jeunes hommes (Photo 9).

L'activité de la confrérie était à l'origine double : une semaine de purifications, centrée sur le vingt-huitième jour du cinquième mois lunaire, s'achevant généralement par la fête de Sengen; et l'expédition (autrefois en bateau jusqu'à Toyohashi 豊橋, ancien Yoshida 吉田) pour l'ascension du mont Fuji au sixième (ou septième) mois lunaire. Les purifications préparaient cette ascension et en étaient la condition. Aujourd'hui, à part quelques exceptions, la plupart des confréries de Sengen de cette côte ont réduit la durée des purifications (d'un à trois jours) et renoncé complètement à ce pèlerinage (depuis une cinquantaine ou une soixantaine d'années, semble-t-il); certaines le perpétuent une fois tous les cinq, dix ans, ou encore les années dites "années du mont Fuji", c'est-à-dire, selon le calendrier chinois, celles du singe, tous les douze ans, et celles de kōshin 庚申, tous les soixante ans. Quelques-unes, très rares, le continuent tous les ans, comme celle de 
Tasō 田曾 (dépt. de Mie, Nanseichō 南勢町). Durant toute la durée de l'expédition, les membres restant de la confrérie et un représentant de la famille de chaque pèlerin pratiquaient autrefois une retraite dans la "demeure de Sengen", puis accueillaient ceux-ci à leur retour par des chants et des danses. A partir de l'époque Meiji, certaines confréries ont aussi rempli le rôle d'association pour les prêts.

Les particularités des pratiques et du culte de Sengen communes à toutes les confréries et spécifiques de cette région côtière sont :

- l'importance de la "montagne de Sengen" pour les gens de mer.

- la double nature de Sengen divinité de la montagne et de la mer.

- des invocations au bodhisattva Sengen héritées du shugendō.

- la rigueur et l'importance donnée aux purifications dans la mer.

- une référence ambiguë au mont Fuji, souvent associé au mont Ōmine, dont la montagne de Sengen est le yōhaisho 遙择所 - "lieu de vénération à distance".

- la présence d'au moins une grande perche de bambou (généralement de deux ou quatre) dite "bonden", remplissant le rôle de "reposoir" (yorishiro 依代) de la divinité Sengen, hissée lors de la fête sur un pin au sommet de la montagne ou de la pointe rocheuse, où celle-ci est vénérée, pour servir d'amer aux bateaux.

- une fête bruyante, parfois disparue, qui à l'origine comportait toujours danses et chants, compétition de force et d'adresse entre les jeunes, parfois des mascarades.

Indépendamment des variations locales formelles de cet ensemble, on constate une différence dérivée de celle des structures de deux types de sociétés distinctes et coexistantes sur ce littoral. Dans les communautés dont l'économie est uniquement ou majoritairement centrée sur la pêche de cabotage aux mains des hommes-soit sur toute la côte de Kushimoto à Hamajimachō 浜島町, tout ce qui concerne Sengen est exclusivement une affaire masculine; tandis que dans la presqu'île de Shima, terre ancienne de collecte sous-marine des coquillages et des algues par plongée en apnée dans laquelle les femmes tiennent une place très particulière, ${ }^{2}$ celles-ci sont venues s'immiscer dans le canevas des pratiques rituelles de Sengen - comme le montre l'exemple d'Azena cité plus haut - d'une façon tout à fait unique dans le contexte de ce culte. Cette participation féminine ne change ni la forme ni le sens de celui-ci, mais elle est l'affirmation de l'importance du rôle de la femme au cœur même d'un culte spécifiquement masculin sur ce littoral, et cela en concordance avec d'autres pratiques rituelles des communautés où est pratiquée la plongée.

Aucune de ces variations ou de ces différences ne porte cependant atteinte au trait fondamental qui caractérise le culte de Sengen dans toutes ces localités de gens de mer : celui-ci n'est pas à l'intérieur d'une communauté locale l'expression d'un groupe limité dont les membres seraient réunis par un culte qui ne concerne qu'eux seuls-alors que cela peut être le cas des Fuji kō des villes et

\footnotetext{
2 Voir A. Bouchy, 1986, 1995.
} 
du Kantō, par exemple. ${ }^{3}$ Que la confrérie de Sengen rassemble une partie ou la totalité des hommes du lieu, c'est l'ensemble de la communauté locale qui est reliée à Sengen par l'intermédiaire de ces derniers : les purifications sont faites au nom de toute la communauté en général et de ceux qui ont des demande plus particulières; chaque maison est purifiée par le passage du bonden, protégée par le petit bambou fiché à l'entrée; les anciens bonden sont mis sur le bord des bateaux pour leur assurer protection et bonne pêche; la fête de Sengen met à contribution d'une façon ou d'une autre tous les membres de la communauté. Par là le culte de Sengen manifeste son appartenance au registre général de l'univers religieux des pêcheurs et son ancrage dans ce milieu où la solidarité est valeur première face au danger côtoyé en permanence.

Loin de résoudre le problème, le parcours de ce littoral sur les traces du culte de Sengen débouche en fait sur une double interrogation : celle des particularités des cultes de gens de mer et de l'identité socio-culturelle qui s'affirme à travers eux; et celle des processus de diffusion et d'implantation des cultes des montagnes, et, plus particulièrement dans un tel milieu, de celui du mont Fuji.

\section{Culte de Sengen et shugen du mont Fuji}

La vitalité et l'unité des manifestations comme du contenu du culte de Sengen peuvent être expliquées, dans un premier temps, par la date apparemment récente de l'implantation de ce culte sur cette ligne côtière. En effet, les plus anciennes inscriptions des statues des oratoires de Sengen, de même que les munafuda 楝札 plaquettes commémoratives de l'édification de l'oratoire placées dans celui-ci - ne remontent pas au-delà de l'ère Genroku 元禄 [1688-1703] (1700: oratoire de Nagashima 長嶋; 1708 : Dainichi nyorai de Kinomoto 木本; 1731 : Dainichi nyorai d'Azena; 1741 : lanterne de pierre de l'oratoire à Nigishima 二木島; 1753 : registre le plus ancien des Kori nakama - Compagnons de purifications - de Tasō; 1757 : Dainichi nyorai de Mikiura 三木浦 - Owase 尾热; etc.). Lorsque cela a été retenu par la tradition locale ou par quelques rares écrits, le culte de Sengen est présenté comme ayant été rapporté d'un pèlerinage au mont Fuji par un homme de la localité, ou par un pratiquant de l'ascèse dans les montagnes (yamabushi 山伏, shugenja 修験者, gyōja 行者), ou parfois instauré lors d'une épidémie pour éloigner celle-ci (Owase, Nagashima, 1700).

Or ces dates coïncident avec le renouveau du culte du mont Fuji déclenché par les activités des deux premiers organisateurs des confréries du Fuji, Fuji kō : Murakami Kōsei 村上光清 (1682-1759), Itō Jikigyō Miroku 伊藤食行身祿 (16711733 ) et leurs disciples, qui suivirent l'impulsion donnée par le fondateur des premiers Fuji kō, Fujiwara Kakugyō 藤原角行 (1541-1646). C'est à partir de cette

\footnotetext{
${ }^{3}$ Iwashina K., 1983 : 33, 139.
} 
époque que le mont Fuji, connu dès l'antiquité comme une terre des adeptes du shugendo - voie de l'acquisition des pouvoirs par l'ascèse effectuée dans les montagnes -, s'ouvrit plus largement aux pèlerinages des non-spécialistes de l'ascèse et que son culte se répandit dans les milieux populaires. ${ }^{4}$ Les $F u j i k \bar{o}$ s'organisèrent d'abord dans les milieux urbains d'Edo et dans les campagnes du Kantō, où leur activité prit parfois l'aspect d'un mouvement populaire à revendications sociales, ce qui leur valut d'être l'objet d'interdictions répétées dans la première moitié du XVIII ${ }^{\mathrm{e}}$ sic̀clc. Mais alors qu'au début des années 1700 les Fuji kō du Kantō n'en étaient qu'à leurs premiers balbutiements, dans le Kansai l'implantation des Fuji gyōnin 富士行人 - pratiquants de l'ascèse du Fuji - datait déjà de deux siècles.

C'est en effet à l'époque de Muromachi, que remonte la plus ancienne diffusion du culte du mont Fuji dans l'ouest du Japon. Elle s'y est faite sous l'égide et la direction des trois principaux ermitages du shugen du Fuji : Chiseibō 池西坊, Daikyōbō 大鏡坊, Tsuji no bō 辻之坊, bettō 別当 - administrateurs - du sanctuaire de Sengen et détenteurs de droits absolus sur le parcours d'ascèse du sommet du Fuji. Ces ermitages étaient établis à Murayama, base de la plus ancienne voie d'accès pour l'ascension du mont Fuji, au sud-ouest de celui-ci. De Murayama était parti Matsudai shōnin 末代聖人 (XII ${ }^{e}$ s.), dit aussi “Fuji shōnin”, le saint homme du Fuji, le fondateur historique de l'ascèse sur cette montagne. C'est le premier dont les chroniques aient conservé le nom et dont la renommée se soit répandue jusqu'à la capitale pour avoir cscaladć lc Fuji "plusieurs centaines de fois" (c'est-à-dire, vraisemblablement, "de très nombreuses fois") et établi un "temple" (sans doute un petit oratoire) dédié à Dainichi nyorai à son sommet. ${ }^{5}$ A Murayama il était luimême vénéré comme la divinité protectrice du Fuji sous le nom de Daitōryō gongen 大棟粱権現 “Apparition circonstancielle ${ }^{6}$ du Grand maître charpentier” (c'est-à-dire du Grand maître ou Fondateur). Matsudai était l'héritier de la tradition du shugendō, relatée dès l'époque de Heian, ${ }^{7}$ selon laquelle En no gyōja aurait été le premier à "voler" jusqu'au sommet, expression légendarisée de la reconnaissance du Fuji comme terre sacrée et lieu d'ascèse par ces adeptes des pratiques ascétiques dans les montagnes. Matsudai avait jeté les bases de la pensée et du panthéon syncrétiques propres au groupe shugen qui s'établit à sa suite à Murayama : le mont Fuji était célébré depuis l'antiquité comme la terre de prédilection des ermites pratiquant les techniques de longévité, comme le mythique mont Hōrai 莑來山 où vivaient les immortels, et aussi comme le siège de la grande divinité Sengen (Sengen ōkami 浅間大神) ${ }^{8}$; avec Matsudai, qui s’appuyait sur les révélations qu'il

4 Voir Endō H.; Gorai S., 1980 : 121-131; Inobe S., 1928 a, b; Iwashina K., 1978 et 1983; Ōmori Y.

5 Honchōseiki 本朝世紀, Kyūan 久安 5.4.16 (1149).

${ }^{6}$ A propos de la traduction du terme gongen, voir B. Fiank : 284-291.

7 Nihon (koku genpō zen.aku) ryoiki 日本(国現報善悪)票異記 I, 28 (822).

× Voir Fujisan no ki 富士山記 (vers 875) de Miyako no Yoshika 都良香 (838-879). 
avait eu lui-même après cent jours d'ascèse totale dans la montagne, le mont Fuji devenait le lieu de vénération de Dainichi, essence originelle de Sengen, qui sera nommé aussi “grand bodhisattva Sengen” 浅間大菩薩. ${ }^{9}$ C'est cette tradition qui se répandit la première et gagna les provinces occidentales. Dès le début du XIV siècle, les disciples de Matsudai avaient organisé Murayama comme un centre shugen, qui instaura les règles d'entrée dans la montagne dites Fujigyō 富士行 ou Fuji zenjō 富士禅定. Ces règles étaient associées à de sévères pratiques de purification préalables, comme c'était l'usage dans toutes les montagnes du shugendo, et furent perpétuées sous le strict contrôle des yamabushi de Murayama durant quatre cent cinquante ans. Murayama était alors le point de passage entre "ce bas monde" de la vie ordinaire et le territoire sacré du Fuji.

Les registres des ermitages nous permettent de savoir que le shugen de Murayama, loin de rester localement circonscrit, avait étendu son influence non seulement dans le Kantō mais surtout vers le Kansai. Ceci s'était fait en particulier par l'intermédiaire des yamabushi de ces provinces qui étaient affiliés au Shōgo.in 聖護院, centre shugen de Kyōto de la branche Tendai, et qui venaient pratiquer l'ascèse du Fuji. En effet, les ermitages de Murayama étaient eux-mêmes rattachés au Shōgo.in et par ce biais s'étaient établis des liens de réciprocité entre eux et les yamabushi de tous les grands centres du Kansai de même affiliation, en particulier ceux du mont Ōmine (Yoshino 吉野 et Kumano), au moins depuis le XVI ${ }^{\mathrm{e}}$ siècle. ${ }^{10}$ Les chroniques des fêtes et rites annuels comme le Hinamikiji 日次紀事 Chroniques des jours (fin XVII') -- (ou plus tard le Shokoku zue nenjūgyōji taisei 諸 国図会年中行事大成 - Compilation illustrée des rites annuels des diverses provinces, début $\mathrm{XIX}^{\mathrm{e}}$ ) - relatent que les Fuji gyōnin du Yamashiro - la région de Kyōto - s'adonnaient aux purifications du Fuji (Fuji kori 富士垢離) dans la rivière, du $25^{\mathrm{e}}$ jour du $5^{\mathrm{e}}$ mois au $2^{\mathrm{e}}$ jour du $6^{\mathrm{e}}$, avant leur ascension du Fuji qui avait lieu au $6^{\mathrm{e}}$ mois (et durait vingt-six jours pour les spécialistes, une journée pour les pèlerins ordinaires); qu'à ces gyōnin spécialistes se joignaient aussi hommes ou femmes qui avaient une demande particulière, car cette purification "était l'équivalent d'une montée au Fuji". Les trois ermitages délivraient les "certificats" de guides au gyōnin spécialistes qui dirigeaient les purifications du Fuji dans les provinces et amenaient avec eux des pèlerins jusqu'à la montagne. Ils leur transmettaient les invocations et les enseignements secrets de Murayama, leur distribuaient des gravures des divinités du Fuji représentées sous leur triple aspect : la triade d'Amida, le bodhisattva Sengen et Dainichi nyorai. Ils les guidaient dans la montagne et tous ces pèlerins avaient le devoir de se faire toujours héberger par le même ermitage. Tout ceci était la base des revenus du shugen de Murayama et de l'étendue de son influence.

\footnotetext{
9 Azuma kagami 吾妻鏡, Kennin 建仁 3.6 (1203).

10) Voir Inobe S., 1928 a : 31-39; 1928 b : 193.
} 
Mais d'une part la distance matérielle et l'assimilation de la purification du Fuji à une ascension furent une cause de rupture à plus ou moins long terme entre Murayama et les confréries locales, qui eurent tendance à ne plus pratiquer le pèlerinage. D'autre part, dès le $\mathrm{XVI}^{\mathrm{e}}$ siècle, copiant Murayama, des yamabushi indépendants avaient ouvert d'autres voies d'accès au nord, à l'est et au sud-est du mont Fuji, tournées vers les provinces du Kantō. Ils ne parvinrent pas à ravir à Murayama sa suprématie dans la montagne, mais c'est de ces bases qu'à l'époque d'Edo partit le mouvement de renouveau du culte du mont Fuji qui donna à celui-ci un aspect shintō très marqué et l'orienta davantage vers une éthique laïque. Entre ces deux tendances s'établit alors une compétition, qui avec le temps devint de plus en plus sévère pour Murayama. Ceci d'autant plus qu'à la fin du XVII siècle, l'exclusivité des droits sur l'entrée dans la montagne dont les ermitages de Murayama avaient joui jusque-là commença à être contestée par le sanctuaire Sengen d'Ōmiya, situé au pied même de Murayama. Celui-ci était administré par les prêtres shintō, et, protégé par le pouvoir central, il finit par l'emporter. C'est dans ce contexte que Murayama tenta de reconquérir les pèlerins du Kansai, qu'Ōmiya cherchait à attirer. Tout au long des $\mathrm{XVIII}^{\mathrm{e}}$ et $\mathrm{XIX} \mathrm{X}^{\mathrm{e}}$ siècles, les ermitages firent œuvre de propagande avec les moyens qui leur étaient propres : l'organisation shugen de l'ensemble du Kansai. Les yamabushi locaux furent chargés de cette campagne. Et l'on peut penser qu'à cette occasion furent implantés, ou réactivés, les cultes de Sengen tout au long du littoral de la péninsule de Kii, territoire sous l'influence des shugen d'Ōmine et des nombreux petits centres locaux.

De fait, les registres du Daikyōbō datés des XVII ${ }^{e}, X^{2} I_{I}{ }^{e}, X^{2}{ }^{e}$ siècles mentionnent le nom de sendatsu responsables du Fujigyō des provinces d'Iga, d'Ise, de Shima, d'Ōsaka et autres lieux du Kansai; fin Edo, on y trouve le nom des confréries d'Ōmine et du Fuji de ces régions qui s'associaient pour les pèlerinages au mont Fuji." Et les documents conservés par les confréries de Sengen dans les ports de la côte orientale de Kii témoignent eux aussi d'une part de ces liens à Murayama, mais également de la contribution du shugen d'Ōmine dans cette diffusion du culte de Sengen.

Parmi ces documents on trouve en effet : des gravures du mont Fuji, vu du sud par la mer, mentionnant l'itinéraire à suivre pour se rendre à Murayama; et, sous forme de gravures sur papier ou d'estampages sur les vêtements des membres des confréries, des représentations de la triade d'Amida, de Dainichi nyorai et du bodhisattva Sengen portant le paraphe "Accès principal Murayama" (Photos 11, 12).

D'autre part, les chants de la fête de Sengen, qui sont aussi ceux du pèlerinage au mont Fuji, retracent tout le périple depuis le port d'origine jusqu'à l'arrivée "au lieu d'hébergement de Murayama" où l'on se purifie "sous la cascade de Fudō". Murayama continua, tant bien que mal, à recevoir et à guider des pèlerins sur le Fuji

"Inobe S., 1928 b : 194; Iwashina K., $1983: 38$. 
jusque dans les années $1935 .^{12}$ Et l'on peut sans doute considérer que la concordance des dates de l'arrêt des pèlerinages pour beaucoup de confréries et de celles de la disparition des derniers yamabushi de Murayama dans ces années 193035 est aussi une marque des liens réciproques qui s'étaient établis entre eux.

Les invocations à Sengen récitées encore aujourd'hui par ceux qui font les purifications dans la mer reproduisent celles du shugen de Murayama - parfois jusque dans leurs altérations - telles qu'elles avaient été imprimées en hiragana par les ermitages dans les années 1818-1830, en guise de "tracts" de propagande pour les pèlerins du Kansai :

Sange no mon

懴悔の文

Sangi sangi

懴悔銭悔

rokkon shōjō

六根清浄

oshimeni hatsu dai Kongōdōji

お注連に八大金剛童子

Fuji wa Sengen, Dainichi nyorai

富士は浅間大日如来

ichini raihai

一に礼拝

namu Sengen Daibosatsu

南無浅間大菩薩

Korewa hachido tonoubeshi

これは八度唱うべし

Fujisan Murayama

富士山村山

Bettō

別當

Sōyakunin ${ }^{13}$

惣役人
Formule de repentance

Repentance, repentance,

purification des six racines

à notre étole les huit grands Kongō dōji

le Fuji, c'est Sengen, Dainichi nyorai

tout d'abord, prosternations

hommage au grand bodhisattva Sengen

A réciter huit fois

Mont Fuji Murayama

Bettō

Ensemble des préposés

Cette "formule de repentance", appelée "nenbutsu de Sengen" par les confréries de Kumano et de Shima, qui est propre à Murayama dans sa seconde partie, est largement utilisée dans le shugendō pour les entrées dans la montagne, de même que les mantras de Fudō myōō et de Dainichi nyorai, qui son récités à sa suite lors des purifications de Sengen.

L'utilisation du bonden lors de la fête de Sengen et en haut de la montagne de Sengen dans tous les ports de ce littoral comme signe de la présence de la divinité est elle aussi un héritage du shugendō, que l'on retrouve dans l'entrée de la

12 Endō H. : $41-44$.

13 Inobe S., 1928 b : 194. Le texte original est écrit en katakana, à l'exception des trois dernières lignes et des caractères 「大日」,「一」,「大」 et $\lceil$ 八度」. 
montagne au mont Haguro 羽黒山 (dépt. de Yamagata), ou au mont Iwaki 岩木山 (dépt. d'Aomori), par exemple. Il semble qu'il soit l'un de ces éléments anciens du shugen du Fuji, qui disparaîtra dans le Kantō pour ne subsister que dans le Kansai, où il est encore partout associé au culte de Sengen de nos jours. "Ils portent le kesa 袈裟 - étole - shugen, secouent le bâton à anneaux (shakujō 錫杖), ...laïcs, ils s'habillent comme des yamabushi et confectionnent des bonden de grande taille qu'ils portent en déambulant en grand nombre dans toute la ville..." : c'est ainsi qu'ćtaient décrits les pratiquants du culte du Fuji à Edo par les deux premières interdictions qui frappèrent ceux-ci en 1775 et 1795, parce qu'ils n'étaient classables ni dans le bouddhisme, ni dans le shintō-ce qui est précisément la caractéristique du shugendō et lui valut d'être la première victime de la séparation du bouddhisme et du shintō sous Meiji. Mais ces bonden n'apparaissent plus dans les interdictions ultérieures et durent disparaître sous l'influence des organisateurs des confréries du Kantō, qui cherchaient à évacuer toute influence du shugendo ${ }^{14}$

Le choix de Dainichi nyorai comme figure principale du culte, et celui du 28 jour de célébration de Dainichi dans le bouddhisme - comme date de la fête de Sengen; de même que l'appellation de Sengen kō et non de Fuji kō ainsi que la graphie de Sengen 浅間 (les Fuji kō du Kantō utilisent celle de Sengen 仙元 révélée par Kakugyō) sont également des preuves indéniables de l'influerice de Murayama. Tandis que la participation du shugen d'Ōmine se révèle à travers des éléments comme : la présence de la statue d'En no gyōja dans les oratoires aux côtés de Dainichi; ou la coexistence des confréries d'Ōmine (Sanjō $k \bar{o}, \bar{O}$ mine $k \bar{o})$ et de Sengen, regroupant les mêmes membres dans la plupart des localités de la côte et jumelant leurs activités.

Tous ces faits sont autant d'éléments qui permettent de considérer le phénomène du culte de Sengen sur ce littoral de la péninsule de Kii comme étant bien dérivé pour tout ce qui concerne les éléments précédemment cités - du culte du mont Fuji, non pas selon la ligne plus récente et située hors du contexte shugen des confréries du Fuji du Kantō, mais selon sa tradition la plus ancienne : celle de Murayama et des Fuji gyōnin. La quasi-disparition de cette tradition confère aux pratiques des gens de mer une valeur de témoignage d'autant plus grande sur ce culte lui-même. Connaître le processus d'implantation de celui-ci dans cette région permet aussi d'avoir un aperçu sur le fonctionnement des réseaux du shugendō à l'époque où celui-ci perdait de plus en plus de terrain dans l'univers religieux.

On peut penser que le travail de propagation des yamabushi fut ici facilité par les particularités de l'univers religieux des gens de mer, qui tiennent toute souillure pour la cause des naufrages et de la mauvaise pêche. Il existe une tradition ancienne de purifications individuelles et collectives pratiquées dans toutes ces localités au moment des grandes coupures du cycle annuel - nuit de l'An et dernière nuit du $6^{\mathrm{e}}$ mois -, mais aussi après une mort - la "souillure noire" kuro fujō 黒不淨 -, une

${ }^{14}$ Inobe S., $1928 \mathrm{~b}: 139,236 ; 1928 \mathrm{a}: 166,171$. 
naissance - la “souillure rouge" aka fujō 赤不淨, ou “souillure blanche" shiro fujō 白不淨 -, ou lors de malheurs répétés, de mauvaise pêche, pour que toutes les causes funestes soient effacées, "lavées". Les purifications de Sengen, investies du pouvoir que leur conféraient les mantras du shugendō et le cadre rituel du culte de Sengen, ont été adoptées comme particulièrement efficaces. C'est aussi ce qui explique qu'avec le temps, s'il ne subsiste qu'un seul élément des pratiques du culte de Sengen, ce soit précisément les purifications dans la mer.

Le culte de Sengen sur cette côte ne serait-il donc que le résultat de cette “implantation" venue de l'extérieur du monde des gens de mer? C'est la question qui surgit à ce point des investigations du côté de l'apport bien réel du shugendō. Cependant celui-ci ne peut expliquer deux des particularités les plus marquantes du culte de Sengen sur ce littoral : l'identification de Sengen à un dieu de la mer; la situation remarquable, et identique dans tous les ports, des petites éminences où est placé l'oratoire de Sengen.

\section{L'au-delà et son double}

Lorqu'on est à la recherche des bases locales anciennes du culte de Sengen le long de cette ligne côtière, il est séduisant de penser que le groupe shugen du mont Asama 朝熊山, situé à la frontière d'Ise et de Shima, et le culte particulier dont cette montagne est le centre ont été des éléments clefs dans l'implantation du culte de Sengen. ${ }^{\text {is }}$ Le mont Asama $(553 \mathrm{~m})$ est, pour toute la population de la presqu'île de Shima qu'il domine, le lieu où vont les âmes des morts et où réside le dieu dragon dispensateur d'eau. Le chemin qui mène à l'oku no in 奥の院 - le temple du fond est bordé d'une véritable forêt de tōba 塔婆 - hautes planchettes commémorant les services accomplis en ce lieu pour les morts - qui peuvent atteindre ici la dimension de piliers de cinq à dix mètres de haut. Sur ces tōba ont été accrochés par les familles des défunts des objets ayant appartenu à ceux-ci : lunettes de plongées, filets, burins à ormeaux pour les plongeuses; pantalons, cravates pour les hommes; poupées, jouets pour les enfants; mais aussi, bâtons de voyage, raquettes de badminton, chapelets... (Photo 13).

La montagne est administrée par le Kongōshōji 金剛証寺, monastère qui fut fondé par un pratiquant de l'ascèse inconnu, mais nommé "Kōbō daishi 弘法大師” dans les récits de fondation. Ceux-ci font du mont Asama l'antique demeure des ermites du tokoyo 常世, le monde immuable de l'au-delà des mers, où se serait manifesté devant le fondateur un prodige du feu céleste. Ce feu, prenant tour à tour l'apparence d'une lumière du ciel et d'un ours d'or, y est présenté comme étant la manifestation d'Amaterasu, assimilée elle-même à l'étoile Myōjō 明星, à Uhōdōji 雨宝童子 et au bodhisattva Kokūzō 虚空藏. ${ }^{16}$ Dès l'antiquité, le mont Asama fut en

\footnotetext{
15 Voir Miyata N., 1965.

${ }^{16}$ Voir Ise Asama dake ryaku engi 伊勢朝熊岳略秝起 et Asama dake giki 朝熊岳儀軌.
} 
effet un centre très prospère du shugendō d'affiliation Shingon, créateur de ce panthéon syncrétique, et célèbre pour sa pratique du gumonjihō 求聞持法 ${ }^{17}$ - “rituel pour chercher à garder en mémoire (la formule suprême par laquelle le bodhisattva Kokūzō peut combler tous ses vœux"). ${ }^{18}$ Mais, comme cela fut le cas pour beaucoup d'autres temples de cette région, après un déclin au Moyen Age, il fut restauré à l'époque de Muromachi par un moine (Tōgaku Monryū 東岳文昱) de la branche Rinzai du Zen, à laquelle il est affilié depuis. Onze temples de Shima lui sont rattachés et par ce biais, tout au long de l'histoire ont été entretenus dans la presqu'île les pratiques et le culte populaire dont Asama est le centre et dont les textes syncrétiques évoqués plus haut sont l'expression savante.

Ce qui a pu être retenu pour rapprocher le mont Asama des montagnes de Sengen, c'est tout d'abord la possibilité du passage d'“Asama" à "Sengen" par glissement homophonique; ce qui aurait pu être le signe de la substitution d'un culte à l'autre : en effet, les caractères 朝熊 d'Ise comme ceux de 浅間 du Fuji peuvent se lire les uns et les autres asa.ma., et 浅間 du Fuji également sen.gen. Asama est un nom qui semble avoir été donné aux montagnes - notamment aux volcans en activité - auxquelles fut reconnu un caractère sacré, comme en témoigne le nombre de celles qui portent ce nom. Asama fut sans doute le terme le plus anciennement utilisé pour désigner ces deux montagnes et leurs divinités, tandis que les lectures d'Asakuma et de Sengen furent secondes et s'appuient sur des interprétations liées aux révélations concernant les divinités vénérées en chacune de ces montagnes. Pour le nom du sanctuaire du mont Fuji en tout cas, ces deux lectures sont bien attestées dans l'Engishiki 延喜式 où à celle de sen.gen est jointe la mention "interprétation secrète". Ce texte cependant présente comme transcription phonétique du nom de l'actuel Asama d'Ise : asa.kuma.jin.ja (doublée de celle de ku.ma.no.jinja) lecture fidèle au contenu de l'Histoire des origines de cette montagne. ${ }^{19}$ Aujourd'hui Asama.ga.dake, Asama yama est le nom couramment donné à cette dernière, tandis qu'Asakuma yama est d'un usage plus savant et rare. Mais s'il est vrai qu'à Shima on appelle parfois "Fuji san" les petites éminences de Sengen sises dans chaque port, jamais je ne les ai entendu désigner du nom d" Asama san". Et l'on ne rencontre pas davantage la confusion des termes ou une utilisation indifférente de "Sengen" pour "Asama", et vice versa, dans l'un ou l'autre de ces deux registres cultuels. Comme on l'a vu plus haut la divinité des petits oratoires peut recevoir plusieurs appellations, mais en fait, à Shima, quand on dit "Sengen san" on parle des petites éminences surplombant les ports où sont hissés les bonden. Bien plus, il est rare qu'un habitant de Shima dise "le mont Asama" pour désigner cette montagne. Le terme couramment utilisé est “Take san”タケさ ん, 啋され : “la Montagne”. Aller en pèlerinage au mont Asama se dit faire le "Take

\footnotetext{
17 Voir Asama dake giki.

is Traduction de B. Frank, 1991: 132.

${ }^{14}$ Engishiki 9, Shinmei 1.
} 
mairi" 岳詣り - "le pèlerinage à la Montagne" -, ou même simplement "faire Take san" - "faire la Montagne" -.

Or, il y a là un autre élément de rapprochement possible entre Asama ct Sengen : le plus grand pèlerinage de l'année au mont Asama a lieu les 28 et 29 juin actuels (autrefois les $28^{\mathrm{e}}$ et $29^{\mathrm{e}}$ jours du $5^{\mathrm{e}}$ mois lunaire), officiellement jours de la célébration de l'anniversaire de la mort de Tōgaku Monryū, qui restaura le monastère. Mais en fait pour toute la population de Shima, ce pèlerinage n'est autre que la célébration annuelle des âmes de tous les morts, pour lesquelles ont été faits en ces lieux des services réguliers et individuels : tout de suite après le décès (avec port de cendres ou de mèches de cheveux), pour la fête des morts de l'été (actuellement entre les 7 et 15 août), pour les grandes dates anniversaires du décès. Les 27 et 28 au soir, le bâtiment dédié à la mémoire de Tōgaku, situé dans l'enceinte du monastère tout en haut du mont Asama, est envahi par une foule de plongeuses des villages de la côte, qui y passent la nuit à chanter et danser les danses de la fête des morts, au rythme d'un grand tambour frappé par l'une d'elles. Quelques rares hommes se joignent à elles : des parents des "nouveaux morts", les défunts de l'année. Car la coutume veut que si leur parenté danse, "les jambes des morts sont légères" (pour le voyage de l'au-delà). Le rire aussi a son rôle : pantomimes et sketchs assez lestes joués par les unes et les autres sont au nombre des morceaux les plus prisés de la soirée. Durant les journées des 28 et 29 juin, l'enceinte de l'oku no in est submergée à son tour par la foule des familles qui viennent déposer devant tōba et stèles mortuaires encens, boulettes de riz, fruits, thé, bouquets de branches à feuillage persistant : "shikibi" - shikimi 樒 ou 杵, anisatum religiosum -, "ashibi" asebi 馬酔木, pieris japonica - et buis, regardées dans la région comme les "fleurs" des morts. Des offrandes de riz sont jetées vers la vallée, au-delà du cours d'eau considéré comme la berge de la "rivière de l'au-delà". De ce pèlerinage est rapporté une branche de shikibi, où sont "descendues" les âmes des morts devenues protectrices, qui sera plantée à l'entrée de la maison, dans un champ. Cette branche est le pendant du bouquet de feuillage persistant (asebi, shii 椎) placé à ces mêmes portes pour accueillir les dieux de la nouvelle année.

Cette concordance de la date du Take mairi et de la fête de Sengen, ainsi que l'existence du shugen d'Asama ont pu donner à penser que le culte de Sengen était une extension locale de celui du mont Asama, sur lequel se serait greffé, à l'époque d'Edo, par l'entremise des yamabushi, le culte du Fuji. Cependant, outre les restrictions faites précédemment, cette hypothèse se heurte à un obstacle majeur, celui de l'homogénéité et de l'étendue des cultes locaux de Sengen bien au-delà de la sphère d'influence de la structure religieuse du mont Asama, limitée, quant à elle, à la presqu'île de Shima et à Ise. Plus au sud sur cette même côte, et en particulier à partir de Nagashima, ce n'est pas au mont Asama mais au mont Myōhō 妙法山 et au temple Amidaji 阿弥陀寺, oku no in de Nachi 那智, situés à l'autre bout de ce littoral que l'on va porter les cendres et demander les services pour les âmes. Et si les activités du shugen d'Asama ont bien laissé des traces dans les villages de la 
presqu'île, il n'en va pas de même pour le reste de la côte, généralement placée sous l'obédience de Kumano et Nachi.

Cependant le rapprochement de Sengen et d'Asama met en lumière une double réalité qui n'apparaît en aucune manière comme contradictoire aux gens de mer détenteurs de ces traditions : parallèlement à cet au-delà du haut des monts Asama et Myōhō où sont censées aller les âmes des morts, il en existe un autre, situé de “l'autre côté de la mer" (umi no kanata ni 海の彼方に) où vont et d'où viennent les âmes des morts et les dieux. Si les pêcheurs et les plongeuses de cette côte veillent à accomplir scrupuleusement encore aujourd'hui les pèlerinages aux monts Asama et Myōhō pour les âmes, ils n'en accordent pas moins une extrême importance aux rites d'accueil des dieux sur les plages durant les trois premiers jours de l'an. Parcourir ce littoral à cette période de l'année permet d'être le témoin d'offrandes de branches d'arbustes à feuillage persistant et de pin, de riz et d'oranges posées à même le sable sur la grève, sur les rochers, jetées dans la mer; d'offrandes de danses, de jeux de marionnettes face au large; d'invocations aux dieux de la mer, aux dieux dragons et aux ancêtres lancées vers l'horizon marin (Photos 17, 18). Il en est de même pour la fête des morts de l'été, dont le Take mairi est un modeste double. Accueil des âmes des morts par le lancer à la mer de petits bateaux de bambous nains, relayés par la lumière de hautes lanternes placées au seuil des maisons; nenbutsu d'accueil et de renvoi chantés face à la mer; danses de toute la communauté sur la grève pour "raccompagner" les âmes, reconduites dans l'audelà par des bateaux de paille chargés d'offrandes et de poupées de papier. Tous ces rites annuellement accomplis sont autant d'expressions de la croyance vivace en un au-delà outremarin, qui serait la résidence des dieux et de toutes les âmes; âmes du passé mais aussi de l'avenir, comme en témoigne la réponse de la plongeuse à l'enfant s'enquérant de "l'endroit d'où il vient" : "Je t'ai ramassé sur la plage Blanche (Shirahama 白浜) et si tu n'es pas sage j'irai t'y reporter!" (tradition d'Ijika 石鏡).

Le problème se pose alors de savoir comment les populations de gens de mer, qui se trouvent ainsi comme prises entre deux au-delà, ont élaboré le rapport de ces deux univers de conceptions apparemment incompatibles et par quelles médiations ce rapport s'est organisé. Une investigation attentive des traditions locales révèle qu'il existe entre ces deux mondes un chemin conduisant de l'un à l'autre et une histoire qui les pose dans un certain rapport. En effet, il n'est presque aucune anse de cette côte où l'on ne puisse entendre raconter l'histoire d'un dieu de la mer "venu s'échouer" sur un récif près du rivage sous la forme d'un tronc d'arbre, d'une pierre, d'un miroir, d'une épée, d'une statue bouddhique, ou même d'un cadavre (Isozaki), et à qui a dû être consacré le petit oratoire, le temple ou le sanctuaire de la localité placé sur la hauteur, face à la mer. Cette installation sur la rive apparaît en effet comme le rite par lequel on propitie une présence qui serait dangereuse si elle restait abandonnée à son errance sur les flots. Ce point de jonction, que constituent les grèves rocheuses et les petites éminences côtières comme lieu de rencontre premier 
des deux univers marin et terrestre, se révèle être une articulation essentielle du complexe religieux qui réunit les cultes de la mer et le monde des montagnes. L'examen de l'élaboration et du fonctionnement de ce rapport ouvre aussi la voie pour une autre approche du problème de Sengen.

\section{Quand les dieux de la mer gravissent les montagnes}

Dans cette région, le meilleur exemple de la dynamique d'un tel rapport, tant pour le développement remarquable qu'il connut, que pour la somme des éléments qu'il offre à l'analyse, est celui de la "montée" de la statue de Kannon d'Ōsatsu 相 差 (Toba 鳥羽) jusqu'au sommet du mont Aomine 青峯山 (336m) situé au cœur de la presqu'île de Shima. Comme le mont Asama, le mont Aomine, terre ancienne du shugendō administrée par le temple Shōfukuji 正福寺 d'affiliation Shingon, est le centre d'un culte particulièrement vivant chez les plongeuses de tout Shima. Mais à la différence de ce dernier et parallèlement au prestige dont jouissent auprès des gens de mer le sanctuaire de Nachi et son temple, le Seigantoji 青岸渡寺, Aomine connut durant toute l'époque d'Edo une véritable vogue de "dieu de la mer" qui s'étendit à tout le pays et égala celle du Kinkasan 金華山 (dépt. de Miyagi) ou de Kompira 金昆羅山 (dépt. de Kagawa). Cette vogue, débordant le cadre du monde des pêcheurs, fut soutenue par la ferveur des équipages des transporteurs (kaisen 回 船) d'Ōsaka, de Nagoya, de Mikawa 三河, ferveur dont témoignent les offrandes encore visibles aujourd'hui dans l'enceinte du temple : lanternes de pierre, plaques commémoratives, ex-voto peints. Actuellement des confréries d'Aomine existent encore chez les pêcheurs et caboteurs de toute la côte du Pacifique depuis Hokkaidō jusqu'à Kyūshū. Or cette renommée d'Aomine repose à la fois sur la situation particulière de cette montagne visible de très loin en mer et sur l'habile exploitation d'un culte local ancien.

L'histoire de Kannon du mont Aomine est rapportée par deux sources : l'histoire des origines du temple conservée au Shōfukuji et une légende transmise à Ōsatsu, village vivant à la fois de la plongée et de la pêche. Cette légende d'Ōsatsu s'articule autour des principaux éléments suivants :

- Hama no Taira Harumitsu 浜の平晴光 : "Taira-de-la-Plage Claire-Lumière", rescapé de l'armée vaincue des Heike 平家, échoue sur le rivage d'Ōsatsu et est adopté comme gendre par l'une des huit familles du lieu:

un étranger "lumineux", revêtu du prestige des guerriers et arrivé par la mer, devient membre de la communauté locale

- Un jour une lumière apparaît sur la mer, la tempête se déchaîne, les habitants effrayés n'osent plus sortir la nuit:

la lumière sur la mer, signe de la manifestation des dieux et des âmes depuis l'époque des mythes, est une puissance dangereuse qui terrorise les populations locales si elle est laissée telle quelle 
- Hama no Taira va jusqu'à la source lumineuse qui se révèle être une statue de Kannon de trois centimètres (1 sun 寸 8 bu 分) montée sur le dos d'une baleine échouée à la pointe rocheuse entre les deux plages d'Ōsatsu (actuel cap de la Baleine) :

l'homme hors du commun remplit le rôle de médiateur entre les hommes et la divinité de la mer; celle-ci est représentée sous le double aspect de la baleine (variante des tortues, wani 鰐 - requins (?) -, et dragons des mythes, ou des sept requins - same 鮫 - considérés à Shima comme les messagers des dieux de la mer) et de Kannon (apport bouddhique, d'autant plus assimilable au concept de l'au-delà des mers que Fudaraku 補陀洛 - Potalaka - le paradis de Kannon est présenté comme une montagne lumineuse située dans les mers du sud; et que Kumano était le lieu d'où certains partirent en bateau pour "s'y rendre" dans un acte rituel d'abandon du corps) ${ }^{20}$

- Il prend la statue et la baleine se transforme en rocher, appelé aujourd'hui "Roche de la baleine", à quelques mètres du cap (Photo 16) :

le premier lieu d"“arrivée" - de vénération - des dieux de la mer est un rocher ou un îlot proche du rivage

- Il garde la statue sur lui (ou chez lui), mais par un rêve Kannon demande à être vénéré sur une hauteur. Il la place dans un oratoire au sommet de la montagne de Guet - Mihari yama 見張山-d'Ōsatsu :

dans un premier temps le médiateur, laïc s'occupant du sacré (type même des gyōja des villages), entretient un culte privé, puis il développe celui-ci en un culte local en portant l'objet de vénération sur la hauteur la plus remarquable $(170 \mathrm{~m})$ du territoire du village (c'est-à-dire à l'endroit que l'on voit le mieux des habitations, d'où l'on voit le mieux la mer et qui est le plus visible du large)

- Un autre rêve lui ayant signifié que ce devait être un lieu encore plus élevé, Hama no Taira porte la statue en haut du mont Aomine, où existait déjà un petit ermitage dont elle devient l'objet de vénération principal. En signe de ses liens avec le mont Aomine, Hama no Taira prend le nom d'Aoyama 青山, qui reste celui de sa descendance aujourd'hui :

le culte est transféré sur la montagne la plus remarquable et la plus proche (qui se trouve exactement dans l'alignement du cap de la Baleine quand on veut rentrer au port d'Ōsatsu) et par là sort du domaine local pour devenir le centre autour duquel s'organisent le temple et le culte du mont Aomine. Le fondateur du culte originel conserve un rapport privilégié avec le Shōfukuji, temple édifié sur le mont Aomine, - en particulier lors des ouvertures de la châsse de Kannon - et avec Kannon, (aujourd'hui encore, une statue de Kannon est vénérée dans la maison Aoyama d'Ōsatsu). Mais Hama no Taira, originellement étranger au village, peut apparaître aussi comme le ravisseur de ce culte de la mer, dont il se sert pour établir la prospérité d'un temple en haut de la montagne.

20 Voir Gorai S., 1975, 1989, 1995. 
Cette légende locale contient des informations essentielles. Elle dépeint le processus d'émergence d'un culte de la mer dans sa relation avec la topographie : récifs et pointes rocheuses sont le lieu de vénération originel des dieux de la mer, et les petites hauteurs dominant les villages de pêcheurs sont le relais de ceux-ci vers la communauté humaine. Les dieux de la mer doivent monter sur la terre, mais rester aussi le plus près des eaux. Et de fait, à Ōsatsu, aujourd'hui encore sur le cap de la Baleine, face au "rocher-baleine", lieu sacré à demi immergé, se dresse un petit oratoire dédié aux dieux de la mer, vénérés aujourd'hui sous le nom de Benzaiten 弁才天 (appelée “Berai san" dans le dialecte local). Le lieu de culte édifié sur la montagne de Guei, le relief le plus remarquable de la localité, était le premier relais, visible depuis le large et le village, de l'oratoire du rivage. De tels lieux sont tous dans un rapport remarquable entre eux ainsi qu'avec l'entrée du port, et servent d'amers (c'est uniquement par la mise en relation de deux ou plusieurs amers que les pêcheurs peuvent déterminer leur position au large). Ils sont aussi considérés comme le "siège" (dit kura et aussi shima le long de ce littoral de Kii) des divinités de la mer. De fait, tout le long de cette ligne côtière, comme sur toutes les autres, les rochers, les récifs, les îlots, les caps et les petites hauteurs remarquables en bordure de littoral qui servent de points de repère aux pêcheurs et aux plongeuses sont appelés “Dieux de la mer 海神”, “Ebisu 恵比須”, “Roi Dragon 竜王” ou “Palais du Dragon 竜宮”. Ces points rocheux sont salués au départ et à l'arrivée des bateaux, et reçoivent des offrandes d'eau de mer, de sake; vers eux sont dirigées les prières lors des sorties en mer et des entrées au port. Dans l'univers marin toujours mobile, ce sont les points fixes vers lesquels peuvent se poser les regards et aller les demandes de bonne pêche et de sauvegarde. C'est sur ces lieux, considérés comme la margelle de leur première "arrivée", que l'on va "chercher" ces dieux, "les plus anciens" du panthéon local, pour les installer dans le sanctuaire de la côte durant le temps de la grande fête annuelle, puis c'est là qu'on les "reconduit". C'est sur ces récifs, où souvent la pêche est interdite en temps ordinaire, que l'on va chercher les poissons, algues ou coquillages offerts à la divinité du sanctuaire local où les dieux de la mer sont vénérés sous de multiples noms. Se pencher vers le champ religieux des usagers de la mer, c'est être amené à reconnaître, comme une généralité sur les côtes, cette utilisation de repères, reliés entre eux par le regard et topographiquement remarquables, investis d'une double fonction et d'une histoire. Ce que je voudrais souligner ici c'est l'univers auquel font référence ces points de repère : si ces récifs et ces petites hauteurs dans les ports sont bien des amers qui permettent donc de retrouver le monde des hommes, ils sont aussi un rappel de l'au-delà de la mer et un relais vers lui, l'axe à partir duquel le regard s'oriente vers l'horizon marin. Bien plus, on peut penser que la fonction d'amer n'est pas séparable, et dépend en fait du rapport qui a été établi entre ce repère lui-même et l'au-delà : par là, ces rochers et ces petites éminences terrestres sont orientés vers le domaine de la mer et tournent le dos à l'arrière-pays. Tous les rites les relient à la mer. Ils matérialisent la croyance pérenne en des 
entités surnaturelles faisant des allées et venues incessantes entre cet au-delà et la terre. Ils parlent d'un monde défini par le champ d'activité des gens de mer, dont ils sont comme la limite côté terre, et servent de renvoi vers cette autre frontière ouverte qu'est l'au-delà outremarin.

Mais la statue de Kannon est montée jusqu'au sommet du mont Aomine. Le texte considéré aujourd'hui comme la version la plus ancienne de l'Histoire des origines du Shōfukuji, et qui fut probablement compilé au début de l'époque d'Edo à partir d'un texte antérieur," présente cette "ascension" d'un tout autre point de vue. La légende d'Ōsatsu, légèrement transformée, y est intégrée à l'histoire, ellemême légendaire, de la fondation du temple exposée en trois parties :

- La fondation du temple est ordonnée à Gyōki 行基 par l'empereur Shōmu 聖武, après un rêve-oracle que celui-ci eut sur le mont Asama, lors d'un pèlerinage à Ise, lui signifiant que la construction d'un temple dédié à Kannon sur le mont Aomine était la condition de l'édification du Tōdaiji 東大寺 de Nara.

- Une statue de Kannon de trois centimètres (1 sun 8 bu) venant du Fudaraku, est portée sur la montagne jusqu'à la roche de Kannon par une baleine qui se transforme en pierre en arrivant dans l'étang du Palais du Dragon devant le temple. En 749 le moine Bodai 菩提 aurait sculpté une “triple" statue - celle du temple actuel - pour y enchâsser la petite statue merveilleuse. Cette grande statue a pour particularité unique de porter sur les reins le koshimino 腰 㝨 (jupe de paille qui était autrefois le seul vêtement porté en mer par les pêcheurs) (Photo 14).

- Suit la description des divers lieux remarquables de l'enceinte du temple dont la "pierre de zazen de Gyōki" (行基の坐禅石), la “roche des lampes" (tōmyõ iwa 燈明岩) dite aussi “pierre des lampes du Dragon” (Ryūtō ishi 龍燈石) car les lampes des dragons y apparaissent.

- Une référence à un "ancien texte" relatant la descente d'Amaterasu sur le mont Aomine sous la forme du disque solaire à l'époque d'Itoku tennō 懿德天皇 (quatrième empereur).

Comme on a déjà pu le voir dans l'histoire du mont Asama - et ce qui est généralement la règle pour les centres anciens du shugendō "ouverts" par des pratiquants de l'ascèse dont la mémoire locale n'a pas conservé le nom -, ce texte donne pour fondateurs au Shōfukuji deux moines célèbres de l'époque de Nara, souvent associés dans les textes anciens. En cela, il ne diffère de la légende d'Ōsatsu qu'au niveau des termes. La signification de ces deux traditions n'étant autre que de poser un être exceptionnel - historiquement connu ou pas - à l'origine du culte autour duquel est bâtie toute l'histoire. A cette différence près que l'un est présenté comme religieux et l'autre laïc. Dans un cas il s'agit en effet de faire reconnaître un temple, et dans l'autre de valoriser une lignée familiale. Cette histoire établit en outre une relation entre le mont Asama et le mont Aomine, qui fut

21 Aominesan Shōfukuji engi 天朗荤山正福寺縁起 [Histoire des origines du temple Shōfukuji du mont Aomine]. Texte manuscrit inédit communiqué par le Shōfukuji. 
effectivement l'un des temples de Shima rattaché au groupe shugen d'Asama. L'existence dans l'enceinte du Shōfukuji de la pierre tombale d'un maître shugen le grand ajari hōin Enchō 大阿闍梨法印円澄 - datée de 1559 permet de faire remonter au moins à la fin du Moyen Age l'existence en ces lieux d'un groupe structuré du shugendō. Le Shiyō ryakushi 志陽略誌 (Abrégé des chroniques du pays de Shima) ${ }^{22}$ écrit en 1713, mentionne lui aussi, comme l'Histoire des origines du Shōfukuji, la fondation par Gyōki à l'ère Tempyō 天平, se référant à une histoire des origines écrite de la main du moine Sonkai 尊海 (sans doute celui du mont Kōya 高 野山, 1625-1695), aujourd'hui disparue. Il nous donne également une idée de l'envergure de ce centre à une époque plus ancienne, puisqu'il mentionne qu' "anciennement il y avait une trentaine d'ermitages" dans l'enceinte du monastère, et que celui-ci, après un déclin au Moyen Age, fut restauré dans les années Jōkyō 昼享 (1684-1688). En outre les documents de l'époque d'Edo conservés dans la presqu'île de Shima sont les témoins de l'importance de l'activité de ces hōin yamabushi 法印山伏 du Shōfukuji qui allaient accomplir les divers rites annuels dans tous les villages, et en particulier à Ōsatsu. ${ }^{23}$ Mais l'histoire des origines du Shōfukuji présente aussi des éléments qui replacent le début des pratiques d'ascèse sur le mont Aomine dans un contexte encore plus ancien et rattachent cette montagne au monde des gens de mer.

En effet, l'entretien d'un feu sacré sur la montagne par les pratiquants de l'ascèse qui y résident est un fait attesté dans de très nombreuses montagnes du shugendō, comme première manifestation de la sacralité du lieu et très ancienne technique ascétique. Ascèse et offrande, ce feu perpétuel est le signe de la présence des dieux et de ceux qui les vénèrent. Il y est présenté comme le "feu des lampes des autels" (tōmyö 灯明), le “feu rituel" (goma 護摩) de la tradition bouddhique, ou le "disque solaire", la "luminosité" des apparitions divines des traditions shintō et syncrétiques, ou comme celui des "lampes des dragons" ( $r y \bar{u} t \bar{o}$ 竜灯), que, selon la tradition populaire, les dragons "montent" en offrande aux buddhas jusqu'aux sommets, pour la nuit de l'An ou la fête des morts en été. Tous ces feux apparaissent dans l'Histoire des origines du mont Aomine, et les lieux où ils sont dits avoir été entretenus sont tous des points d'où l'on aperçoit tout l'horizon au large d'Ise, de Shima et de Kumano. De fait, jusque dans les années 1910-1920 un feu fut entretenu par les moines du temple sur la roche des lampes comme repère pour les bateaux. Il en était de même au mont Kinkasan, sur le mont Misen 弥山 de Miyajima 宮島 (dépt. de Hiroshima), sur le mont Takuhi 焚火山 - “Montagne où l'on fait du feu" - (Oki 隠岐, dépt. de Shimane). C'est ce feu qui fut le véhicule, et ceux qui l'entretenaient les agents, de la montée de la lumineuse statue de Kannon d'Ōsatsu jusqu'en haut du mont Aomine. C'est ce feu, sous sa forme surnaturelle,

${ }^{22}$ Texte en trois volumes d'Ashida Shōho 芦田省甫, dont il n'existe que des exemplaires manuscrits.

${ }^{23}$ Miyata N., 1965. 
qui est devenu le signe de la protection de Kannon : les dizaines d'ex-voto peints du Shōfukuji représentent les apparitions merveilleuses de la lumière rayonnante de Kannon que les fidèles d'Aomine voient apparaître dans les tempête, en quelqu'endroit de l'archipel qu'ils soient, pour les guider vers le port.

Aussi terrible que soit la tempête et noire la nuit sur la mer, pour celui qui aura invoqué ne serait-ce qu'une seule fois le bodhisattva (Kannon du mont Aomine), celui-ci fera jailiir la lumière de son toupet frontal (byakugō 白毫) et apparaître une lampe sacrée (tomyo) pour le sauver du péril (Photo 15).

mentionne une version moderne de l'histoire des origines du Shōfukuji.

Les modalités réelles de ce transfert restent dans l'ombre. Un responsable du culte d'Ōsatsu s'installa-t-il sur la montagne? Un ermite d'Aomine s'empara-t-il de la tradition locale? Y eut-il "vol" de la statue merveilleuse par les gens d'Aomine, comme cela se passe souvent dans le cas de cultes qui acquièrent un certain renom (il existe sur cette côte de nombreuses traditions de vol de statues miraculeuses par les habitants de villages voisins). En tout cas, il y eut en quelque sorte "vol de l'histoire" - dans les deux sens du terme - de Kannon d'Ōsatsu. Dans toutes les versions de l'histoire des origines du temple, la statue de Kannon est dite "avoir volé" directement depuis la mer jusqu'au sommet du mont Aomine. Les premières étapes du culte de Kannon à Ōsatsu, son origine de dieu de la mer, et parfois même jusqu'à la présence de la "baleine porteuse" y sont totalement occultées. Au mieux il est mentionné que cette statue venait de la mer au large d'Ōsatsu. Pour les gens du Shōfukuji, c'est en haut du mont Aomine que Kannon réside et de là qu'il dispense sa lumière. Il y eut ainsi tout un travail de recomposition de la légende originelle pour créer cette Kannon-divinité de la montagne, protectrice des gens de mer. De cela les groupes shugen sont coutumiers, et la très riche littérature des engi, histoires des origines, de tous leurs centres en est le meilleur témoignage. Le groupe du shugen d'Aomine sut habilement s'approprier une tradition orale des plus spécifiques du monde de la mer et l'implanter sur un site exceptionnel - la plus haute montagne de toute la presqu'île de Shima et la plus visible du large - pour asseoir au long des âges la puissance et la prospérité de sa structure religieuse. Aujourd'hui encore toutes les plongeuses de Shima portent au cou la médaille de Kannon d'Aomine; s'inclinent en joignant les mains vers la montagne avant de commencer leur travail de plongée; rendent grâce au retour; ne manquent jamais le pèlerinage au mont Aomine les 18 (jour de célébration de Kannon) janvier et 18 juillet; en rapportent des ofuda 御札 - charmes de protection - qui sont mis sur les bateaux; les pêcheurs eux aussi viennent en groupe, non seulement de la région mais aussi de lointains départements, pour des mairi annuels.

Mais l'intégration du culte local d'Ōsatsu à l'univers de cette montagne shugen, signifia sa fossilisation en tant que culte d'une divinité de la mer, comme le symbolise cette pétrification de la baleine dans l'étang du Dragon en haut de la montagne. Et c'est ce sur quoi je voulais plus précisément attirer l'attention. 
Kannon du mont Aomine est bien resté dans le panthéon des gens de mer, mais son implantation sur la montagne y a suscité un bouleversement. Tandis que les anciens cultes aux divinités des mers "venant se poser" sur les récifs et les petites éminences côtières sont un rappel de l'au-delà outremarin, le culte du mont Aomine focalise le regard vers la montagne, en tant qu'univers sacré en soi. C'est sur le sommet que réside le pouvoir salvateur. Se reposer sur la protection de Kannon du mont Aomine, c'est oublier son appartenance à la cosmologie de la mer voulant que les divinités "vont et viennent", c'est tourner le dos à l'au-delà outremarin. Et tout le travail du shugen d'Aomine a dû être de convaincre les populations environnantes de cette réalité par tous les artifices de l'élaboration des croyances, dont il était le premier bénéficiaire. Il fallait en effet que cette polarisation sur la montagne soit suffisamment forte pour que les gens de mer éprouvent la nécessité de monter y demander la sécurité en mer, alors que de multiples divinités "viennent" depuis toujours apporter leurs bienfaits et leur protection à ceux qui les vénèrent directement sur le littoral...

L'ensemble formé par la légende d'Ōsatsu et l'histoire des origines du Shōfukuji est exemplaire car d'une part il est le témoignage de l'émergence et du développement, dans le monde des représentations des gens de mer, d'une conception d'un au-delà fixé sur les montagnes; il permet d'autre part de reconstituer les différentes étapes d'un processus dont souvent les traditions locales ne conservent qu'une partie. Il permet en outre de relier ces jalons les uns aux autres : les cultes des dieux de la mer sont progressivement transférés du littoral vers des sites de plus en plus élevés, qui ont entre eux des rapports topographiques précieux pour les gens de mer. Il fallait qu'existe d'abord ce culte de Kannondivinité de la mer, pour que puisse naître celui de Kannon-divinité de la mer-en-lamontagne. L'instauration d'un culte sur la montagne de Guet du littoral d'Ōsatsu a été le point tournant de ce devenir. Mais cette étape médiane est celle qui s'est éteinte avec le temps. Ont subsisté le culte du récif-baleine, divinité de l'au-delà de la mer, entretenu par la communauté locale d'Ōsatsu; le culte familial de Kannon dans la maison Aoyama; et celui de Kannon du mont Aomine, développé par le shugen de cette montagne - dont la présence était aussi une condition indispensable au processus - en un culte intégré à un registre religieux complexe, et qui par là s'est répandu tout le long du littoral du Pacifique.

\section{Sengen : un axe pour deux visions du monde}

Cette excursion du côté du mont Aomine, quoi qu'il puisse paraître, nous mène au cœur du problème de Sengen. Au cours de mes pérégrinations de port en port sur les traces de Sengen, une chose me frappait : les petites hauteurs sur lesquelles se trouve l'oratoire de Sengen sont aussi le relief le plus remarquable, celui qui surplombe le plus immédiatement chaque anse, et par là le plus susceptible d'être choisi comme 
amer lors du retour dans le port. Etant donné les caractéristiques de l'univers religieux des gens de mer évoquées précédemment, il pouvait sembler bien improbable qu'un culte n'ait été instauré en ces lieux qu'à partir de l'époque d'Edo.

Et en effet, sous la couverture du culte de Sengen se laisse découvrir en ces mêmes lieux un support beaucoup plus ancien. Dans de nombreux cas, i'oratoire de Sengen n'est autre que l'entassement naturel et spectaculaire d'énormes blocs de roches rondes, laissant en son centre un espace où est simplement déposée la statue de Dainichi nyorai. Pins, camphriers énormes et plusieur fois centenaires poussent à proximité. Ces caractéristiques sont exactement similaires à celles de l'oratoire du dieu de la montagne (yama no kami), situé ailleurs, et sont toujours la marque de l'extrême ancienneté de l'investissement religieux de l'endroit, repéré pour sa configuration étonnante (Photo 8).

On trouve aussi parfois sur le même site des divinités qui, selon la tradition locale, y sont vénérées depuis une date bien antérieure à celle de l'introduction du culte de Sengen. Ainsi à Kinomoto 木本 (Kumano), l'oratoire de Sengen, situé sur la montagne du Gongen, dite aussi de Gonbee, qui surplombe la mer, fut précédé par celui d'Ōji gongen 王子権現, auquel il fut associé avant que celui-ci ne soit réuni au grand sanctuaire local. Or, sur tout ce littoral, les pêcheurs vénèrent des divinités de la mer nommées Ōji - Prince -, qui ont toujours pour siège soit des récifs à demi immergés en bordure de grève, soit des pointes rocheuses sur la côte, dites “Ōji de terre" (riku no Ōji 陸の王子), mises en rapport avec un récif qu'elle surplombent, appelé “Ōji du large” (oki no $\bar{O}_{j i}$ 沖の王子). Le long de la côte bordant la seule ville de Kumano on en relève quatorze, mais d'autres existent également plus au nord et plus au sud, et, semble-t-il, sur toutes les côtes du Japon. ${ }^{24}$ Ces Ōji sont à la fois des amers et des divinités de la mer dont le culte est identique à celui des Ebisu, Dragons, Palais du Dragon que l'on retrouve partout en des endroits similaires. (Ces données maritimes permettent de considérer sous un autre angle la nature des quatre-vingt-dix-neuf $\bar{O}_{\mathrm{ji}}$ qui jalonnent la route ancienne du pèlerinage aux trois montagnes de Kumano. Mais ceci nous éloigne de Sengen). Ce que cette association de Sengen avec l'un de ces "Princes de la mer" révèle c'est la nature première de la divinité Sengen telle qu'elle est vénérée chez les gens de mer.

C'est aussi ce que vient corroborer l'assimilation de Sengen au dieu Dragon (“Ryūjin” 竜神) rencontrée à Shima (Kuzaki 国崎); ou la croyance plus généralement répandue voulant que le pin de la montagne de Sengen soit celui auquel les Dragons portent leurs lampes en offrande, dans la nuit du $28^{\mathrm{e}}$ jour des premier et cinquième mois lunaires, jours de célébration de Sengen. Et les bonden, qui sont d'abord dressés sur le rivage pendant la durée des purifications, puis montés en grande pompe jusqu'à l'oratoire sur la petite hauteur lors de la fête de Sengen, sont à la fois offrande à Sengen divinité résidant sur la montagne et "reposoir"

\footnotetext{
${ }^{24}$ Voir Gorai S., 1989.
} 
(yorishiro) de Sengen divinité venant de la mer. Quant aux divers rites du culte de Sengen, ils s'intègrent aussi dans la tradition vivace des purifications et des fêtes de la mer qui ont lieu généralement deux fois l'an chez les gens de mer. Ainsi l'offrande de cailloux ramassés au fond de l'eau lors des purifications et déposés sur l'autel de Sengen est-elle à rapprocher du rite d'offrande du galet ou de la pierre pris au rocher d'Ebisu dans la mer, et portés dans l'oratoire sur la grève pour la célébration d'Ebisu au $11^{\mathrm{e}}$ mois lunaire. Lampes des Dragons, bonden, offrandes de cailloux, purifications en mer sont autant de rappels d'une même relation première existant entre la cosmologie de la mer et la divinité appelée Sengen.

Quand les gens de mer qui entretiennent son culte parlent unanimement de Sengen comme étant un "dieu de la mer", ils évoquent ce substrat ancien qui n'appartient pas au registre originel du bodhisattva Sengen-Dainichi nyorai importé en ces milieux par les soins du shugen de Murayama. Le phénomène de l'adoption de Sengen par les populations de ce littoral peut être considéré comme un cas d'assimilation d'un culte "étranger" à un ancien culte local des dieux de la mer, qui en intégrant la nature du culte nouveau se trouve caché et agrandi d'une dimension qu'il n'avait pas à l'origine : la relation avec le culte du mont Fuji. En cela ce phénomène est semblable à celui de l'instauration de cultes à des divinités appartenant à une tradition complexe shinto : Sukunabikona 少彦名, Kompira, Inari 稻荷, Hachiman 八幡, ou bouddhique : Benten 弁天, Yakushi 薬師, Namikiri Fudō 浪切不動, sur ces caps, récifs et montagnes du littoral - topographiquement parlant exactement identiques aux montagnes de Sengen - qui autrement seraient restés dédiés à Ebisu, au dieu Dragon ou à une anonyme "divinité de la mer" (kaijin, umi no kami 海神). C'est ce qu'apprend un périple le long de n'importe quelle côte ou même simplement l'examen d'une carte au cinquante millième. Les petites montagnes de Sengen correspondent au second jalon du schéma des étapes de la "montée" des cultes des dieux de la mer vers les montagnes, tel qu'il est présenté dans l'histoire du mont Aomine. Toutes ces petites hauteurs des localités du littoral durent à l'origine être indifféremment le "reposoir" et des âmes des morts et des dieux invités à venir de l'au-delà de la mer lors des fêtes annuelles, avant de subir des évolutions diverses selon les hasards de l'histoire locale et des influences extérieures. La superposition d'une figure cultuelle plus élaborée est la garantie de survie des anciennes divinités locales transformées. Inversement l'appropriation de cultes locaux par les centres shugen contribue souvent à la disparition de ce jalon intermédiaire. Ainsi, si l'on veut rechercher un lien entre le mont Asama et Sengen, on peut supposer qu'il existe bien, mais sans doute plutôt dans le sens d'une focalisation sur Asama d'un ensemble de petits cultes locaux préexistants de la presqu'île de Shima, eux aussi utilisés habilement par le shugen d'Asama pour devenir un centre religieux prospère. Mais un culte des gens de mer transporté dans un registre religieux complexe et institutionnalisé subit une "spécialisation" : généralement les âmes des morts ne sont pas célébrées à l'endroit où les pêcheurs vont demander la protection en mer. Asama et Aomine ont en cela Myōhō et Nachi 
pour pendant à l'autre bout de ce littoral de Kii. Inversement, les rites pour les dieux de l'An et les âmes des morts, que perpétuent les communautés locales au Nouvel An et lors de la fête des morts, sont accomplis sur les mêmes plages et sur les mêmes récifs.

La particularité locale du culte de Sengen est donc, plus encore que cette assimilation et cette spécialisation elles-mêmes, l'ensemble avec lequel l'ont adopté les gens de mer de tout ce littoral. Là encore c'est l'univers de la mer qui semble être la clef du phénomène : en effet tous les pêcheurs de cette région disent que par beau temps le mont Fuji est visible du large des côtes de la mer de Kumano. Ainsi le si prestigieux Fuji est-il lui-même tout à la fois un amer et la terre originelle de la vénération de Sengen. Et les montagnes locales de Sengen sont ce pivot médian, simultanément rappel du monde outremarin par la nature fondamentale de sa divinité et relais de l'au-delà fixé sur le mont Fuji; elles sont l'axe matériel et symbolique d'une superposition de deux visions du monde. Mais le cas de Sengen se révèle vraiment exemplaire, puisque l'au-delà, tel que le shugen le plus ancien du mont Fuji l'avait élaboré dès l'époque de Nara, est précisément le monde outremarin transporté sur terre : le mont Hōrai...

Ile "de la mer orientale", séjour des immortels où l'on va chercher le remède d'immortalité, le mont Hōrai 蓬來山 (Peng Lai) de la tradition chinoise, entré dans le monde des représentations japonaises dès l'époque ancienne, fut localisé sur le mont Fuji à la suite, semble-t-il, d'un jeu de va-et-vient de cette tradition entre la Chine et le Japon. ${ }^{25}$ L'instrument en fut l'histoire de Jofuku 徐福 (Xu Fu), cet émissaire de l'empereur des Qin (fin III ${ }^{\mathrm{e}} \mathrm{s}$. av. J.-C.) parti pour chercher le remède d'immortalité et qui aurait en fait atteint le mont Fuji où il se serait fixé. Par là, le mont Fuji est devenu en quelque sorte l'au-delà des mers sur terre. Mais, je mentionnerai en passant que la terre de Kumano, qui fut également regardée comme l'autre monde, fut aussi assimilée au mont Hōrai. On trouve et à Shingū 新宮 et à Hatasu 波田須 (Kumano) la "tombe" de Jofuku. A Hatasu, Jofuku est clairement associé à un ancien culte d'Ebisu. Et les multiples traditions de l'implantation de Jofuku que l'on peut rencontrer tout au long des côtes de l'archipel sont à relier à des cultes plus anciens de divinités de la mer, ancêtres fondateurs, venant de l'audelà outremarin. L'identification du mont Fuji au paradis de l'au-delà des mers élaborée par le shugen de cette montagne est un phénomène parallèle à l'appropriation de la légende de Kannon d'Ōsatsu par le shugen du mont Aomine, ou à l'instauration par celui du mont Asama d'un espace rituel pour les âmes des morts au sommet de celui-ci. Considérées du point de vue de la cosmologie de la mer, ces recompositions procèdent du développement d'un panthéon et d'une vision de l'au-delà qui s'appuyent bien sur des représentations et impératifs propres à l'univers des gens de mer (croyance en la venue des âmes et des dieux depuis l'audelà outremarin; nécessité de montagnes-amers devenues sacrées), mais qui ont été

\footnotetext{
25 Gorai S., 1983, J. Pigeot 1993: 127-169.
} 
"sédentarisés" en haut des montagnes.

Le fait, qu'avec le temps, les aspects liés à la dynamique propre au monde de la mer disparaissent du discours véhiculé par les groupes shugen administrant ces montagnes vient confirmer l'insertion de ces panthéons dans un univers de représentations différent. Ainsi Kannon ne "redescend" pas du mont Aomine. Et dans les villages du littoral, ce n'est pas du mont Asama, mais toujours de la mer que l'on accueille les âmes des morts. Seule la montée est valorisée et sert de justificuation aux pèlerinages. De même, l'évocation du mont Ilōrai semble avoir disparu assez tôt du contenu du culte du mont Fuji. Pour ceux qui pratiquent le culte de Sengen, le Fuji est plutôt un au-delà chtonien avec le parcours initiatique de la "grotte de la matrice", ou le mystère de la grotte Hitoana 人穴 - Trou d'homme (mentionné dès l'époque de Kamakura dans l'Azuma kagami 吾妻鏡), ${ }^{26}$ lieu d'ascèse secret au pied du Fuji que visitent les pèlerins et où, dès le Moyen Age, la croyance veut que commencent les enfers et le paradis. ${ }^{27} \mathrm{C}$ 'est aussi un au-delà miaérien, mi-terrestre, celui du sommet de la montagne, où résident Sengen, Dainichi nyorai, mais également les dieux et les buddha attachés à chacun des sites sacrés, dont les guides expliquaient les origines secrètes lors du pèlerinage sur le Fuji, et dont on récitait les noms inscrits sur les gravures rapportées de Murayama. C'est aussi le monde de Konohana no sakuya hime, fille du dieu de la montagne, du panthéon shintō. En cela le mont Fuji est semblable à toutes les autres montagnes du shugendō. Que ce soient les plus grands centres shugen comme ceux des monts Haguro, Hikosan 英降!l, Ōmine (Yoshino, Kumano), Ishizuchi 仿鎚山, I lakusan 白

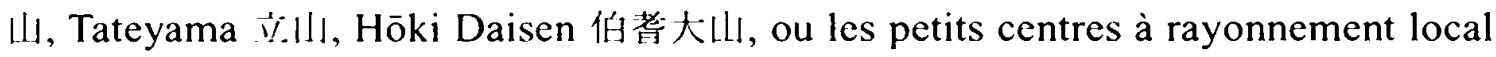
semblables à ceux d'Asama ou Aomine, tous sont considérés depuis l'antiquité comme le lieu où l'on peut rencontrer les morts, avec leurs "vallées des Enfers" où l'on accomplit les rites pour les âmes, et les dieux-buddha descendus sur les sommets. Le monde originel de Sengen auquel font référence les représentations héritées du shugendō est en tout cas, symbolisé par la silhouette en cône du Fuji peint sur les ex-voto qui rappellent chaque pèlerinage de la confrérie, un univers de lave et de roches totalement différent du monde de la mer.

Les représentations qu'ont les gens de mer de l'univers marin et outremarin sont pour la plupart lettre morte pour ce qui constitue la majorité de la population terrienne de l'archipel. Les conceptions du palais des dragons ou du mont Hōrai véhiculées par la littérature populaire et savante, ou celle des divers paradis bouddhiques situés à l'ouest ou au sud de la mer, ont été la source principale des seules images vagues et lumineuses de l'au-delà des mers généralement répandues. De telles représentations font partie du patrimoine des peuples de la mer au Japon, comme l'a montré Origuchi Shinobu dans ses nombreuses études sur les rites

26 Azuma kagami, Kennin 2.6.3 (1202).

27 Voir Fuji no hitoana zōshi 富士 $の$ 人穴草子 (époque de Muromachi), le premier texte mentionnant le périple d'un homme dans l'au-delà dont cette grotte est l'entrée. 
d'Okinawa et les visiteurs de l'au-delà (marebito まれびと), ${ }^{28}$ et aussi Yanagida Kunio, qui cherchait par là à vérifier son intuition d'une peuplade venue du Pacifique sud. ${ }^{29}$ Selon cette cosmologie, l'au-delà des mers - nommé "nirai kanai" dans les Ryūkyū, ne no kuni, haha no kuni, "pays des racines" ou "de la mère" dans les mythes des Chroniques du Japon -, est le lieu d'où viennent périodiquement ces visiteurs, dieux, ancêtres, pour apporter abondance et prospérité à leurs descendants. A Shima, outre les rites évoqués plus haut qui témoignent de la pérennité de cette même croyance, des contes parlent encore d'un au-delà sous-marin. Ainsi cette variante de la visite d'une plongeuse au palais sous-marin du dieu de la mer, exact pendant féminin de l'histoire d'Urashima Tarō 浦島太郎, mais qui se distingue de celle-ci par nombre d'éléments qui appartiennent à l'univers des représentations des plongeuses :

Une plongeuse se rend au palais du Dragon (ou au sanctuaire du dieu “Isoko", c'est à dire Izawa no miya 伊雑宮 d'Isobe 磯部) situé au-delà d'un portique de pierre par quarante ken 間 - quelque soixante-dix mètres - de fond. Elle y est régalée de banquets durant trois jours (ou trois mois, ou un an) et en revient avec une boîte qui lui assurera bonheur et prospérité, si elle la porte sans l'ouvrir au sanctuaire d'Isobe. Mais la curiosité des gens du village la conduit à violer l'interdit. Il sort de la boîte une immense moustiquaire qu'il est impossible de renfermer à l'intérieur. La boîte et la moustiquaire sont déposées telles quelles au sanctuaire. La plongeuse devient aveugle (ou bizarre, ou pauvre) comme le sera une personne de sa famille à chaque génération (tradition d'Anori 安乗).

Mais les pêcheurs et les plongeuses du littoral de Kii ont perpétué, parallèlement à ces images d'un au-delà outremarin et sous-marin source de bienfaits si les règles et les rites sont respectés, une vision différente beaucoup plus glauque et dramatique. Autre monde, monde de l'autre, la mer est en effet aussi le monde du quotidien et de l'identité. Pour eux, il n'y a pas de solution de continuité entre l'espace où s'exerce l'activité source de leur subsistance et cet au-delà outremarin ou sous-marin : Itago ichimai shitawa, jigoku 板子--枚下は地獄 - “ Sous la planche de la coque, les Enfers" -, dit le proverbe. Fantômes hideux vêtus de blanc, umibōzu 海坊主 - le "moine de la mer" - ou Dandaraboshi ダンダラボシ - le géant à un œil et à grande bouche, qui cherchent à couler les bateaux en les remplissant d'eau; tomokazuki "compagne de plongée" - ce double maléfique de la plongeuse qui l'attire au-delà de sa réserve de souffle pour lui ravir la vie; poissons qui parlent et jettent des sorts; pieuvres et serpents maîtres des grottes sous-marines; requins, baleines, dragons gardant des récifs interdits, où toute violation du tabou entraîne la mort;

28 Voir le développement de sa pensée depuis “Hahaga kunihe, tokoyohe 妣が国へ、常世 へ" (1920), “Ryūkyū no shūkyō 琉球の宗教” (1923), “Kodai seikatsu no kenkyū 古代生活の研 究” (1925), jusqu’à “Kokubungaku no hassei, marebito no igi 国文学の発生・まれびとの意 義” (1927). Voir bibliographie ci-dessous.

${ }^{29}$ "Kaijō no michi". 
corps des noyés qu'en aucun cas on ne doit laisser dériver sous peine d'être victime d'une fatalité tenace de mauvaise pêche, mais qu'il faut remonter à bord et enterrer sur la berge : pour les gens de mer, les flots, sur lesquels se déroule une existence consacrée à la poursuite de prises toujours fuyantes, jamais assurées, sont aussi peuplés de tous ces êtres sombres et errants, allant et venant entre horizon et rivage. Monde des dieux, des ancêtres et pouvoir générateur de prises nourricières, mais aussi monde des morts et de la mort, la mer est pour eux l'espace ouvert où convergent l'ici et l'au-delà. Elle est le domaine premier des prises ct des dons mutuels, des échanges de la vie et de la mort.

Ces données de base de l'univers des gens de mer permettent d'évaluer la force de l'impact que durent avoir dans l'univers des représentations des gens de mer l'implantation et le développement de la symbolique de l'autre monde des montagnes, réplique de son homologue outremarin, mais démultiplié, localisé et matérialisé par sa fixation sur les sommets. L'examen du culte de Sengen, axe médiateur sur lequel viennent s'assembler les deux strates de l'univers religieux qui le composent, permet de mettre en lumière la dynamique de l'élaboration de cette double vision du monde.

A travers le processus de superposition du culte "extérieur" de Sengen sur des cultes plus anciens aux dieux de la mer se laissent en effet apercevoir et le phénomène d'une focalisation du regard sur les montagnes; et le rôle fondamental du shugendō comme agent de l'implantation de données nouvelles. Culte de la mer subsistant à travers une recomposition montagnarde de son contenu marin, le "phénomène Sengen" sur cette côte de Kumano peut être considéré comme le témoignage de l'un de ces développements, dont on sait peu de chose, qui se sont produits à l'intérieur du système des représentations des gens de mer. Alors que les récifs, les îlots et les petites hauteurs-amers-sièges sacrés n'étaient à l'origine qu'un support de la relation des populations du littoral avec l'univers de la mer et son audelà ouvert - par leur fonction de "reposoir" momentané des dieux de la mer et des âmes venant y "aborder" - ces mêmes lieux sont devenus aussi - par le biais de cet impératif du monde de la mer qu'est la nécessité des amers - les relais d'un au-delà fixe et limité au domaine d'une montagne précise, localisée dans l'arrière pays. Le littoral, qui fut le lieu premier, et de l'activité de pêche et de collecte en mer avant l'usage de la pêche au filet au large, et du rapport avec la terre, a été ce territoire médian à partir duquel le monde des gens de mer s'est développé dans toutes ses dimensions. ${ }^{30}$ Il est resté tout au long de l'histoire l'espace privilégié des rencontres, des conflits et des médiations entre les univers maritime et terrien.

Pêcheurs et plongeuses ont conservé le rapport ancien avec les grèves rocheuses, qui restent le lieu privilégié de leurs activités et de la cosmologie ouverte vers l'audelà outremarin. Mais, l'ancrage sur le littoral fit que s'instaura une dynamique d'ouverture vers les terres; il permit la rencontre avec un système religieux

30 Voir Sakurada K. 
complexe, par l'intermédiaire duquel fut intégrée une autre conception : celle de dieux et d'âmes "sédentaires". L'adoption de cette vision de l'au-delà par les gens de mer a été l'un des facteurs générateurs de l'illusion qu'ils appartenaient à la même "culture" et partageaient fondamentalement le même monde de représentations que les sédentaires de l'intérieur des terres. Se pencher aujourd'hui sur le monde de la mer conduit souvent à se faire le rapporteur de l'histoire des glissements de sens progressifs, voire des inversions ou des "oublis", qui se produisirent à l'intérieur des systèmes de représentations des gens de mer sous l'impact répété de ses multiples rencontres avec les autres groupes sociaux; mais cela permet aussi de montrer, à travers ces transformations, l'histoire de la recherche d'un équilibre et d'une cohérence, facteurs d'identité, toujours remis en question.

En tentant de retrouver le processus par lequel le culte de Sengen s'est implanté chez les gens de mer du littoral oriental de la péninsule de Kii, mon objectif n'était pas de faire une ethnographie, ou un historique du phénomène. J'ai tout d'abord essayé ici de déméler l'enchevêtrement des multiples données du problème, telles qu'on peut les appréhender aujourd'hui, afin de mieux faire apparaître les divers registres référentiels. Mais ce n'était là qu'une manière d'aborder, par l'un de ses nombreux aspects, une question beaucoup plus vaste qui demande d'autres développements : la mise en relation des réalités et transformations du monde de la mer à travers l'histoire et du problème de l'occultation de celui-ci à l'intérieur du système de représentations régissant l'idée que le Japon se fait de lui-même.

L'investigation des systèmes de représentations des gens de mer est un moyen d'approche de ce problème. Et l'étude du culte de Sengen, complétée par l'éclairage qu'apportent ceux des monts Asama et Aomine, constituait pour cela un exemple privilégié tant par la qualité des données accessibles que par l'existence de documents qui en permettent l'approche (ce qui est loin d'être le cas pour tous les cultes des gens de mer). Dans l'univers des gens de mer, le passage d'une vision orientée vers la mer, à la fois lieu de vie ancestral et autre monde un et indifférencié, à une vision intégrant celle du monde des autres, jalonné d'une multitude d'au-delà matérialisés et arpentables, peut sans doute être rapprochée des transformations que suscitèrent, dans l'ordre économique et technique, l'implantation sur les terres et l'établissement d'échanges avec les montagnards et les agriculteurs sédentaires de l'arrière-pays. Or on sait, par la résistance qu'opposèrent à la sédentarisation les derniers héritiers des "nomades de la mer", les ebune 家船 - "bateaux-maisons" - et les shaa シャア de Kyūshū, ou les nōji 能地 de Hiroshima, ou même les groupes de plongeuses de Kii, pratiquant les migrations temporaires sur les côtes du Japon (jusque dans les années 1950) et de Corée (jusque vers la fin du siècle dernier), combien l'attachement à la terre, l'enracinement dans les criques étaient opposés à la conception du monde et de la vie qu'avaient les peuples de la mer. ${ }^{31}$ Par là est posé le problème des diverses composantes de la société japonaise et des rapports

\footnotetext{
${ }^{31}$ Voir Itō A., Kawaoka T., Miyamoto T., Noguchi T.
} 
que celles-ci entretiennent entre elles.

Une grande partie des gens de mer, ceux qui ne sont pas des agriculteurs venus à la pêche à cause de conditions géographiques favorables - et plus particulièrement les plongeuses de toutes les lignes de côtes, les plongeurs des îles du sud et les derniers ebune de la mer intérieure - sont les héritiers de ces nomades de la mer. Mais leur histoire reste à écrire car leur identité socio-culturelle - celle de leurs divers groupes - n'a jamais été prise en compte en tant que telle. Quelques pionniers de l'ethnologie japonaise se sont penchés sur le problème dès le début du siècle, mais firent peu d'émules. Depuis une décennic des historiens, notamment des médiévistes, et aussi des archéologues, des anthropologues se penchent avec un intérêt accru sur le monde de la mer et se sont mis à reconsidérer leur conception même de la société japonaise à la lumière de documents nouveaux (ou d'un nouvel examen des documents connus) révélant l'importance de tous les gens de mer dans l'histoire et l'économie nippones. ${ }^{32}$ Mais le travail à faire est considérable et la situation critique. C'est en effet non seulement la conception de l'histoire et de la société, mais la société japonaise elle-même, dans sa structure et son fonctionnement, qui a toujours été dominée par l'idée - à valeur de sens commun et de conscience identitaire - qu'elle était une société agricole centrée sur la riziculture. ${ }^{33}$ Une telle conception repose sur la non-reconnaissance de l'identité et de la place réelles des peuples de la mer dans un archipel comptant quelque vingt-huit mille kilomètres de côtes et plus de trois mille îles et îlots. Or cette vision de la société a ćtć vćhiculćc au long des siècles par les pouvoirs, l'idéologie et l'éducation. Elle a été à l'origine de l'occultation du monde la mer, alors même que celui-ci par sa participation effective a toujours contribué à l'édification de ce qu'est le Japon.

Sur ce sujet peu de documents offíciels sont disponibles, car c'est précisément à ce niveau que le monde de la mer a été occulté. Restent la masse inexplorée des documents locaux, le foisonnement des traditions orales, les fêtes grandes et petites, les rites de la vie et de la mort, du travail et des circonstances exceptionnelles, le domaine des comportements et des représentations. Les pêcheurs, les plongeuses du littoral oriental de la péninsule de Kii sont détenteurs de telles traditions. Ceux des autres lignes côtières aussi. Tous se montrent empressés à les transmettre et partout leur accueil est chaleureux. Mais les recueillir implique d'arpenter les ports et les grèves, de monter sur les bateaux, de fouiller les archives des coopératives maritimes, des sanctuaires, des temples, des particuliers. Ce monde de la mer est en outre en danger : la pêche de cabotage cst de moins en moins pratiquée, la plus jeune génération de plongeuses a dépassé la quarantaine et il n'y a pas de relève. En ce sens, plus que jamais l'univers des gens de mer se révèle un "monde flottant".

Rechercher une vision différente et plus exacte de la société japonaise

32 Voir en particulier les onze volumes de la collection Umi to rettó bunka dirigée par Amino Yoshihiko et al.

3.3 Amino Y. 1994. 1995. 
demanderait cependant de faire apparaître, non seulement tout ce qui, de cet univers propre aux pêcheurs, plongeuses et à tous ceux qui vivent de la mer et des eaux en général, est resté dans l'ombre; mais aussi la part de celui-ci dans l'ensemble des données socio-culturelles du Japon; cela impliquerait de décrypter les processus de transformation que traversèrent les divers éléments du monde de la mer sous l'impact répété des multiples rencontres avec les milieux de montagnards, d'agriculteurs, de citadins; de reconnaître les points de convergence et d'affrontement, les agents de médiation cntrc ces univers; enfin, de démêler les raisons complexes de cette occultation. Ainsi une compréhension plus exacte des peuples de la mer offre la possibilité d'un rééxamen de ce qui est tenu pour acquis sur la société japonaise : la connaissance de ses réalités, mais aussi la vision qu'elle a d'elle-même et l'image - "consensuelle et homogène" - qu'elle a cherché à en donner (ceci permettant de s'interroger sur les raisons et le type d'efficacité de cette attitude), ou encore les rapports avec d'autres sociétés (ceux qu'elle a pu entretenir, par le truchement des gens de mer, avec les pays d'Asie Orientale et d'Asie du SudEst, par exemple). C'est la possibilité d'une approche renouvelée des représentations de l'identité et de l'altérité au Japon. 


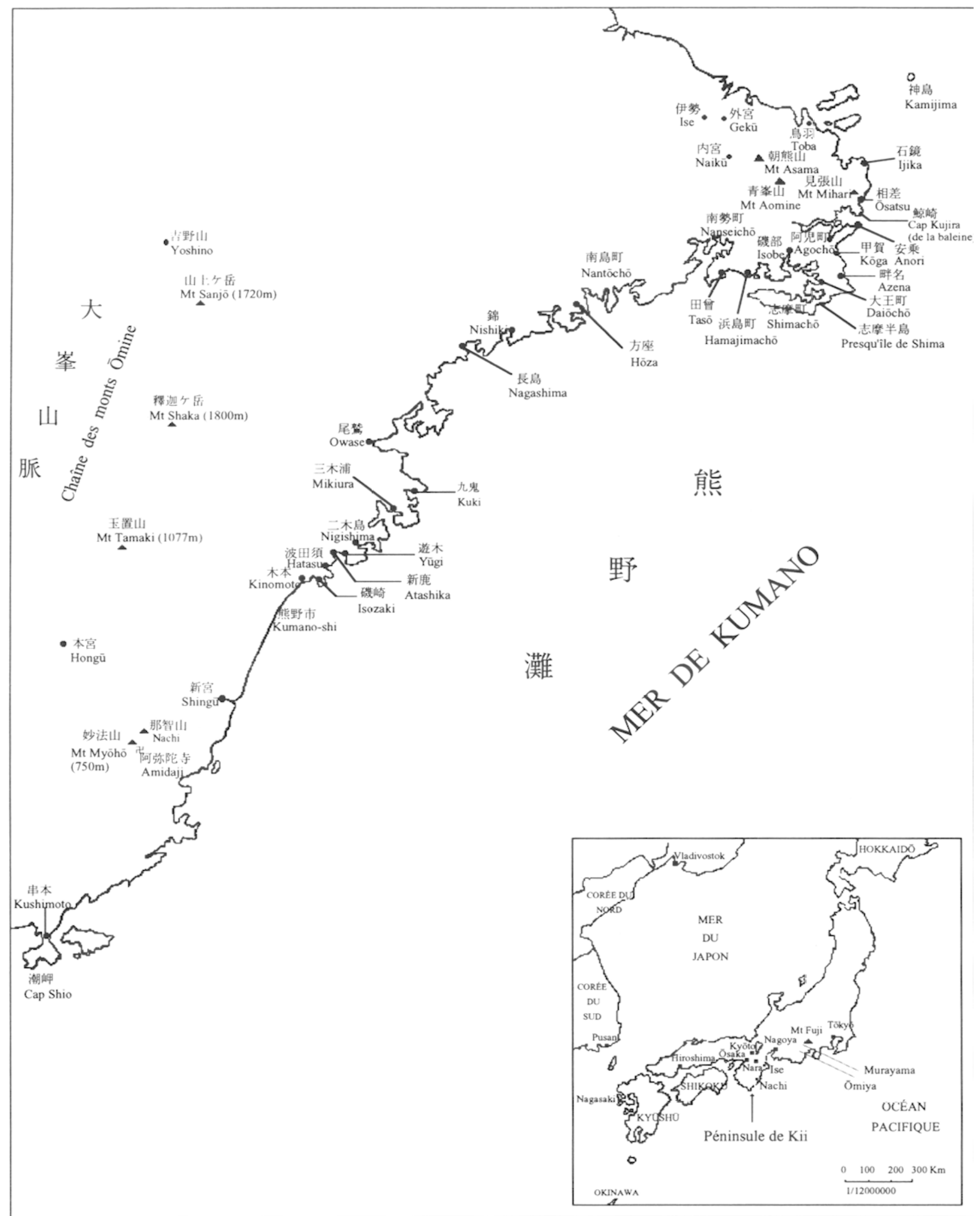

ISE, SHIMA ET LA CÔTE ORIENTALE DE LA PÉNINSULE DE KII 


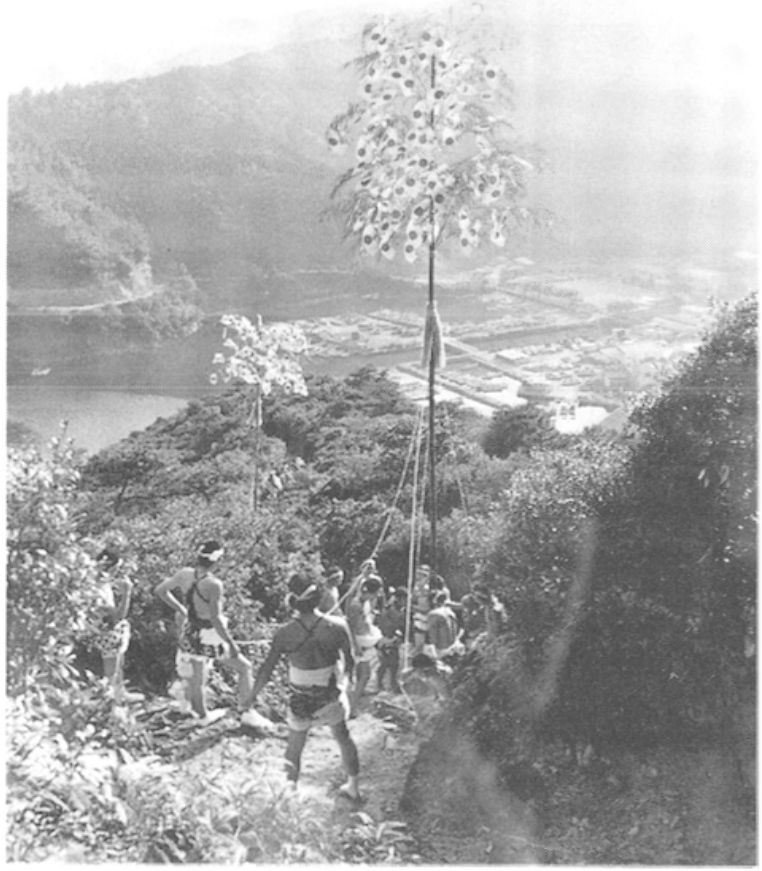

1 - Montée des deux honden par le groupe des jeunes sur la montagne de Sengen dominant le port de Hōza (Nantōchō) lors de la fête de Sengen (le $28^{\circ}$ jour du $5^{\circ}$ mois lunaire).

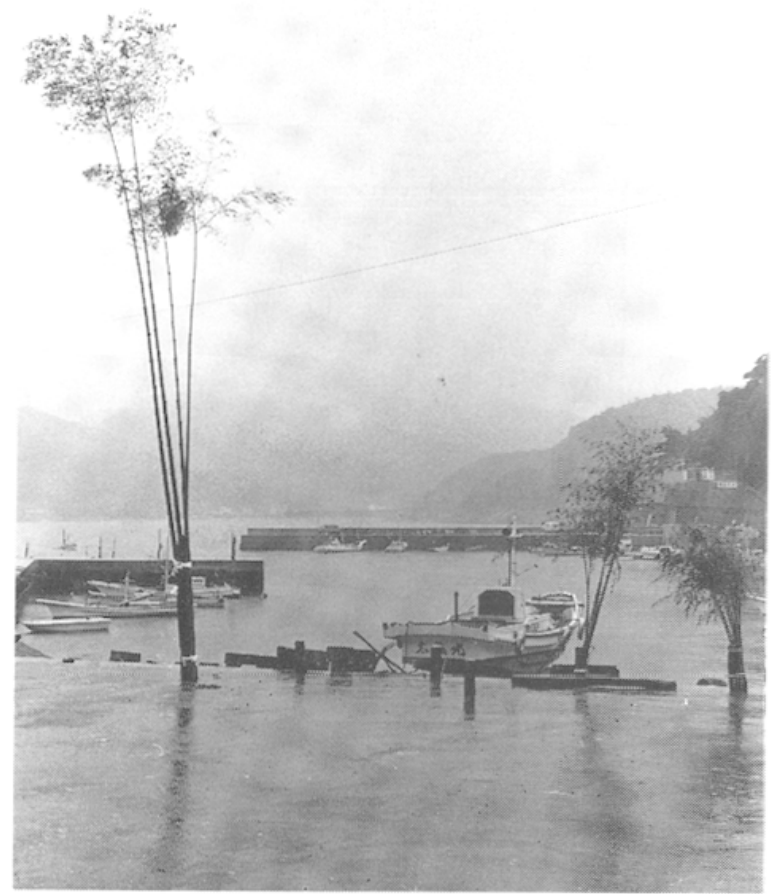

3 - Les deux "grands bambous" et les deux honden plantés sur le port d'Isozaki pour la fête de Sengen avant qu'on ne les hisse au sommet de la montagne de Sengen (le $30^{\circ}$ jour du $5^{\prime \prime}$ mois lunaire).

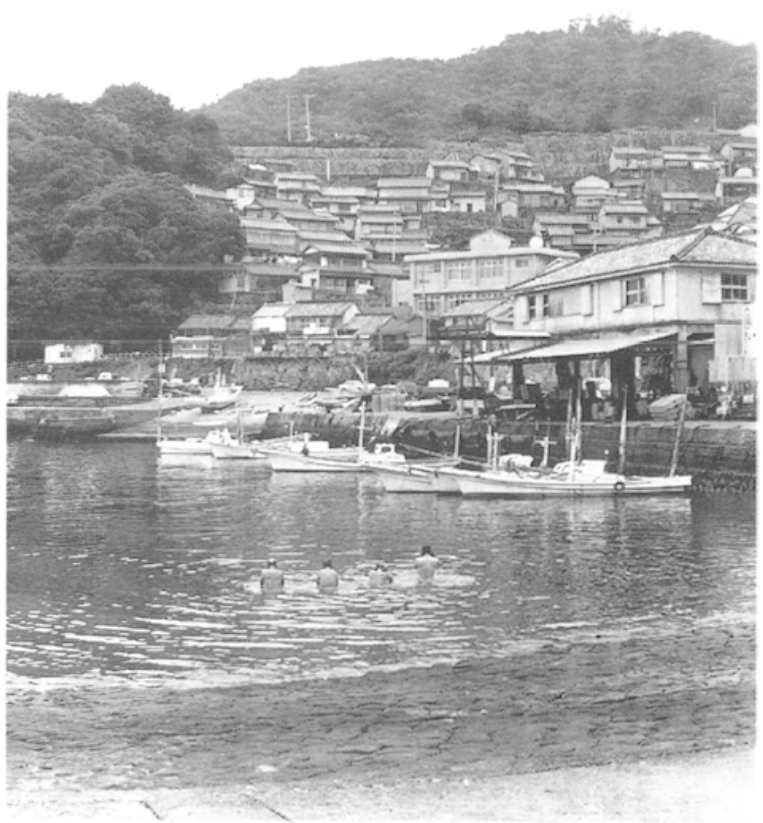

2 - Purifications des gyonnin face à la montagne de Sengen (le sommet sur la droite) dans le port d'lsozaki (Kumano). A gauche, la forêt du sanctuaire de la localité.

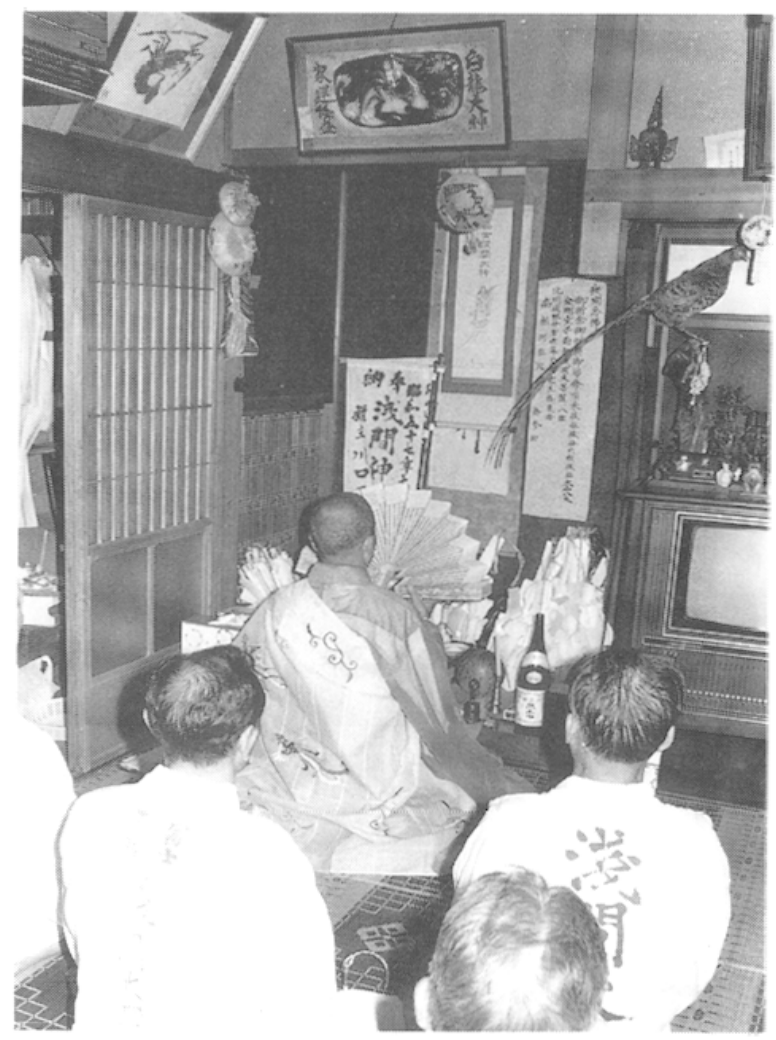

4 - Le moine du temple de la localité accomplit un service bouddhique devant l'image de Sengen ōkami dans la "demeure de Sengen" lors de la fete (Isozaki). 


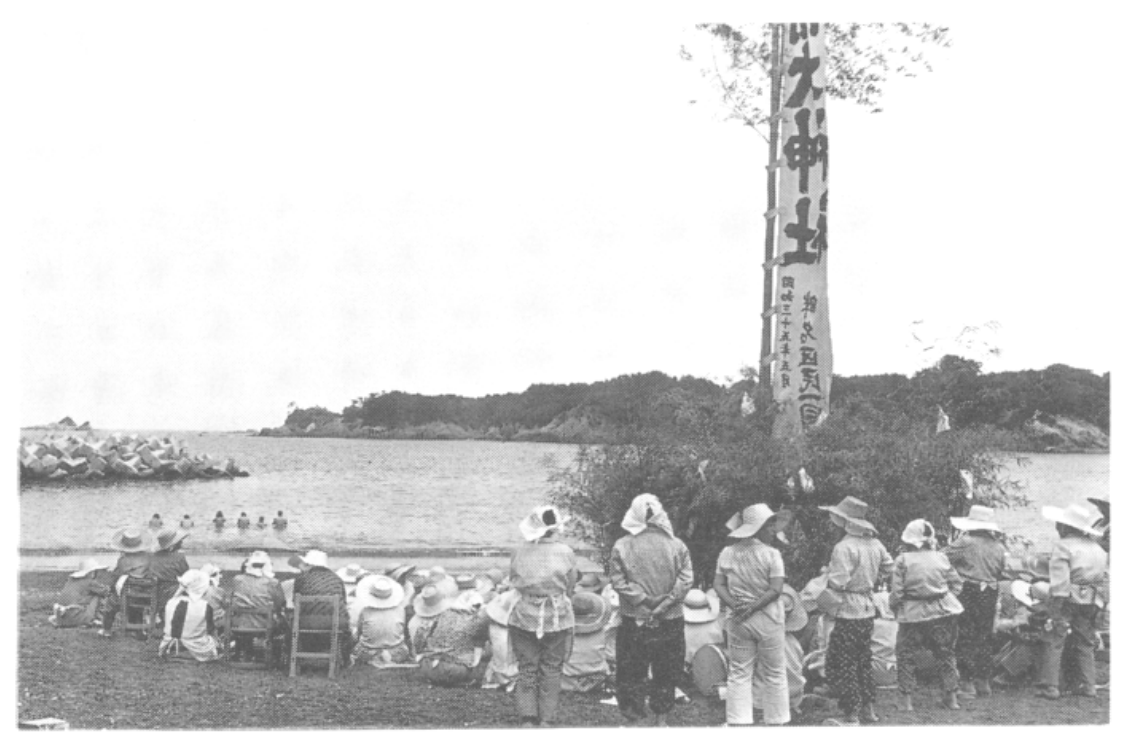

5 - La "purification en commun" des hommes (des pêcheurs) d’Azena (Daiōchō) dans la mer, le jour de la fête de Sengen (le 28 juin), sous le regard de toutes les femmes (des plongeuses) qui entourent le bonden et l'oratoire de Sengen placé au milieu des petits bambous, face au large.

6 - Après les purifications dans la mer. les hommes hissent le bonden en haut du pin de Sengen, le jour de la fête (Azena).

7 - Le port de Nigishima (Kumano) et la montagne de Sengen (qui le domine immédiatement sur la gauche) au sommet de laquelle on peut apercevoir le grand camphrier de Sengen et, sur la gauche de celui-ci, le bonden qui sert d'amer.
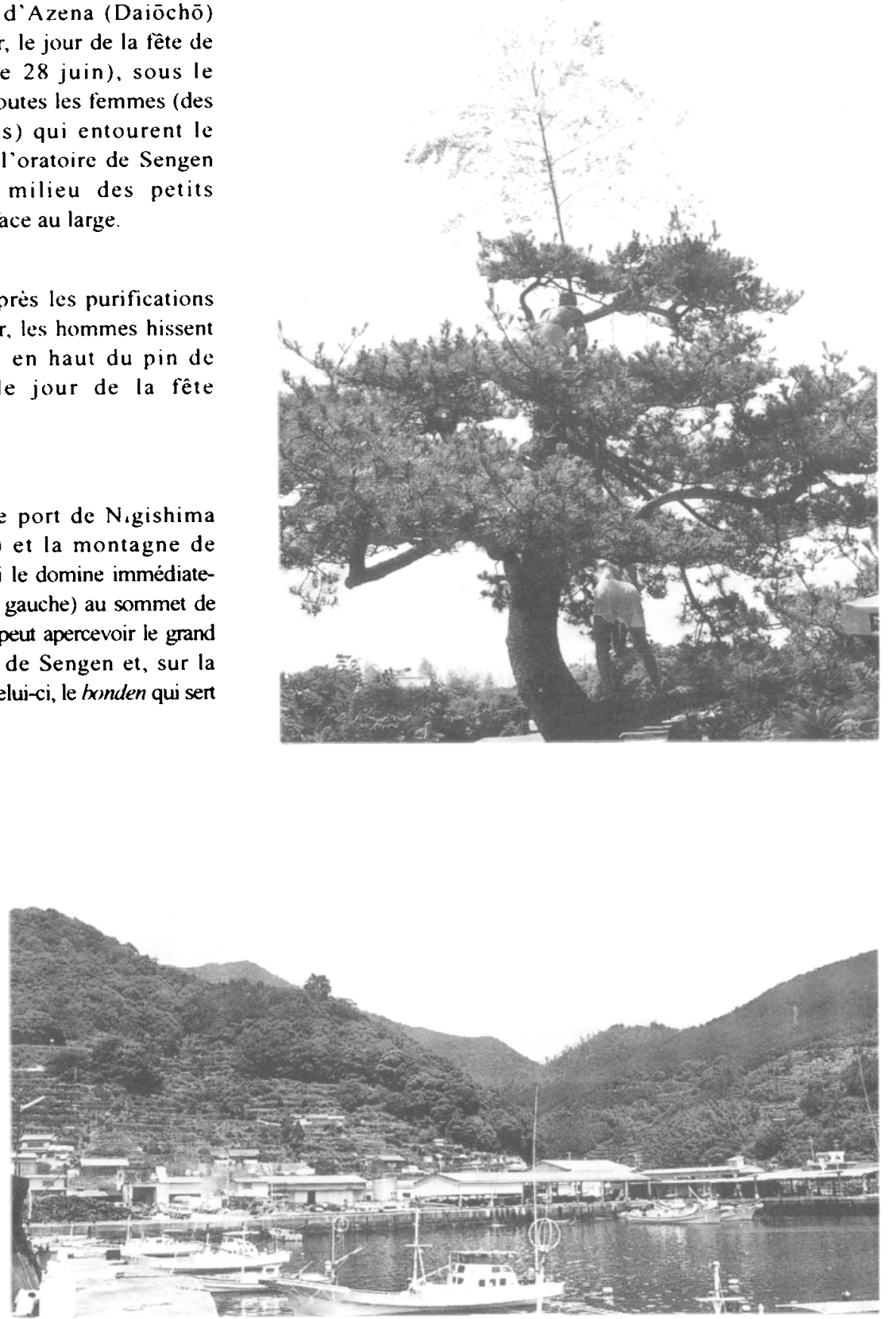


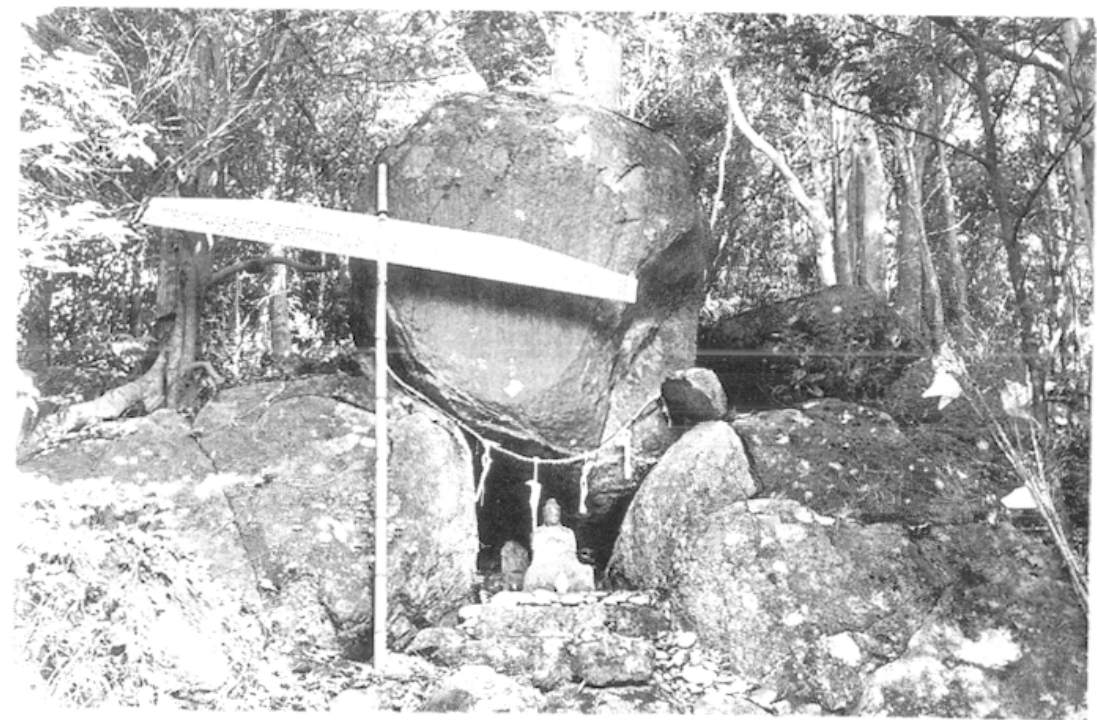

8 - En haut de la montagne de Sengen à Yugi (Kumano) l'oratoire de Sengen, fait d'un amas naturel de grosses roches, où est vénéré Dainichi nyorai. Sur la droite on aperçoit les petits bambous avec des gohei, déposés lors de la fête qui vient d'avoir lieu. Sur la gauche, est fixée sur un bambou une plaque de bois, offerte "en demande de protection en mer et de bonne pêche", portant le nom des pêcheurs membres de la confrérie de Sengen et celui de leurs bateaux.

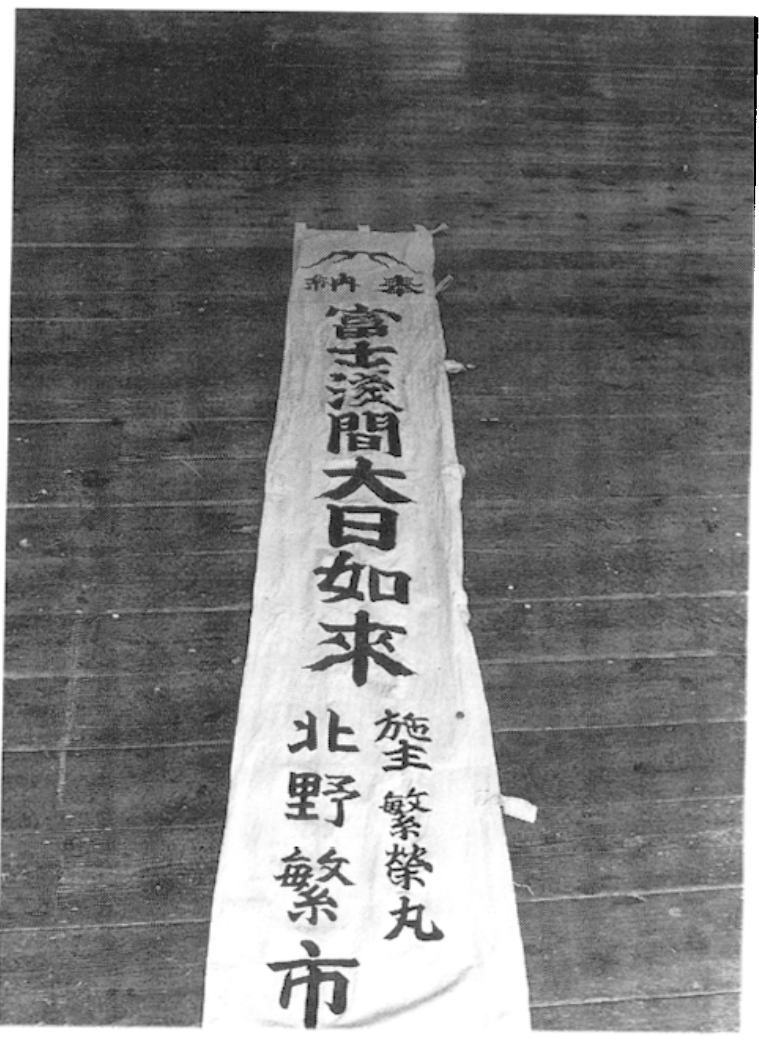

9 - Bannière au nom de "Fuji Sengen Dainichi nyorai" pour la fête de Sengen, offerte par le propriétaire d'un bateau de pêche de Nigishima (Kumano).

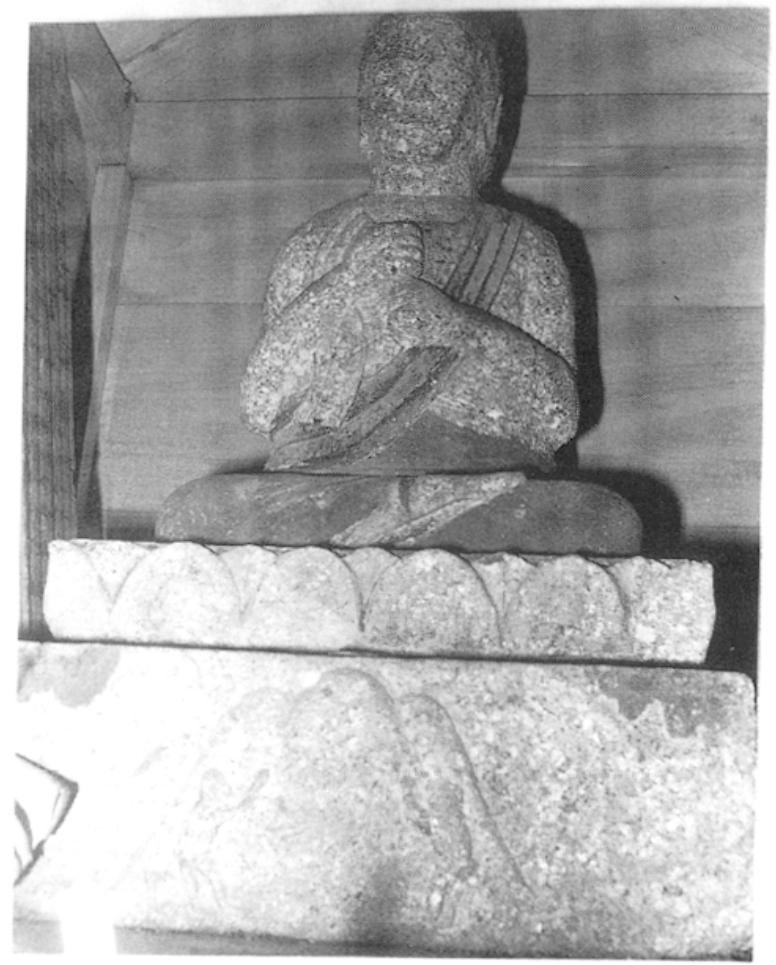

10 - "Sengen san", statue de Dainichi nyorai, dit aussi "Konohana sakuya hime san", vénéré dans l'oratoire de Sengen en haut de la montagne du même nom à Atashika (Kumano). Sur le socle est visible un bas relief représentant le mont Fuji et les deux singes qui lui sont associés. 
Les trois manifestations de la divinité du mont Fuji telles qu'elles étaient représentées à Murayama
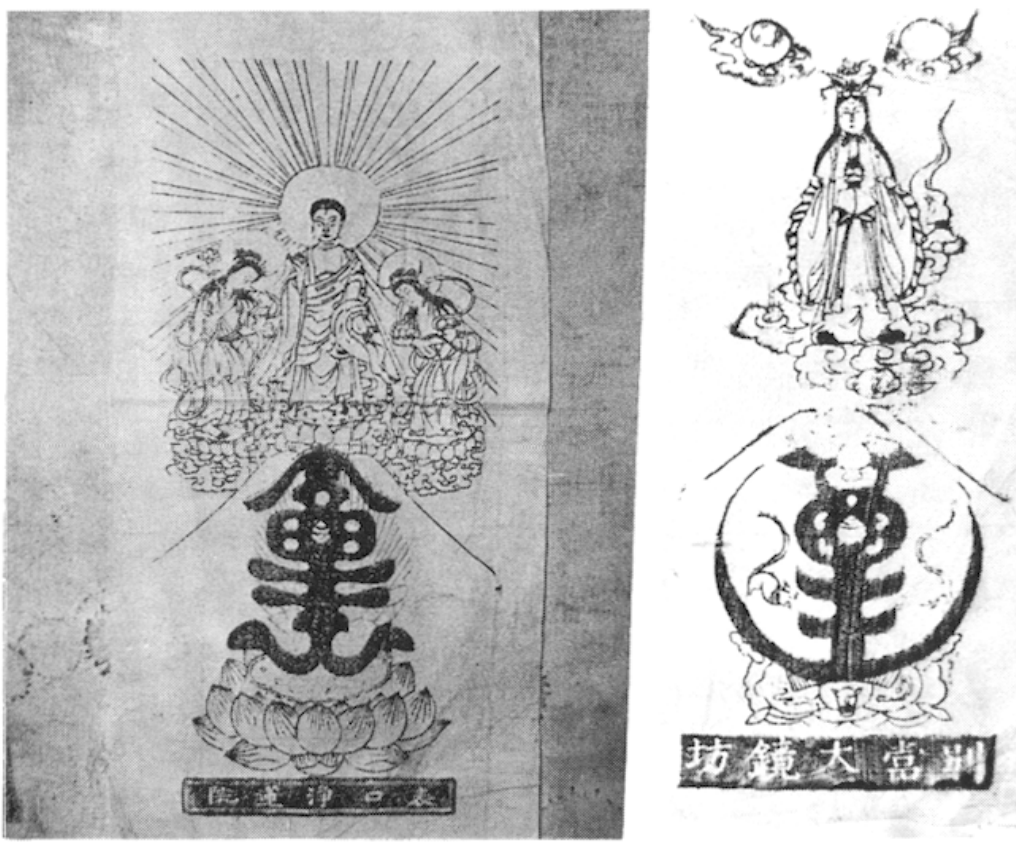

11 - Deux ofuda - charmes de protection - de Murayama conservés par la confrérie de Sengen de Tasō (Nanseichō). Celui de gauche représente la triade d'Amida dominant le sommet du mont Fuji, lui-même placé au-dessus des caractères "Fu.ji.san, mont Fuji" - sur le lotus et au-dessus de l'inscription “Omote.guchi Jóren.in - Entrée principale Jōren.in 仍進院" (nom de l'un des nombreux petits ermitages dépendant des trois grands ermirages de Murayama).

Sur celui de droite, c'est Konohana sakuya hime, entre le soleil et la lune, qui domine le mont Fuji et les inscriptions "Fuji san" (en caractères verticaux) et ceux de "Bettō Daikyōbo", l'un des trois grands ermitages de Murayama.

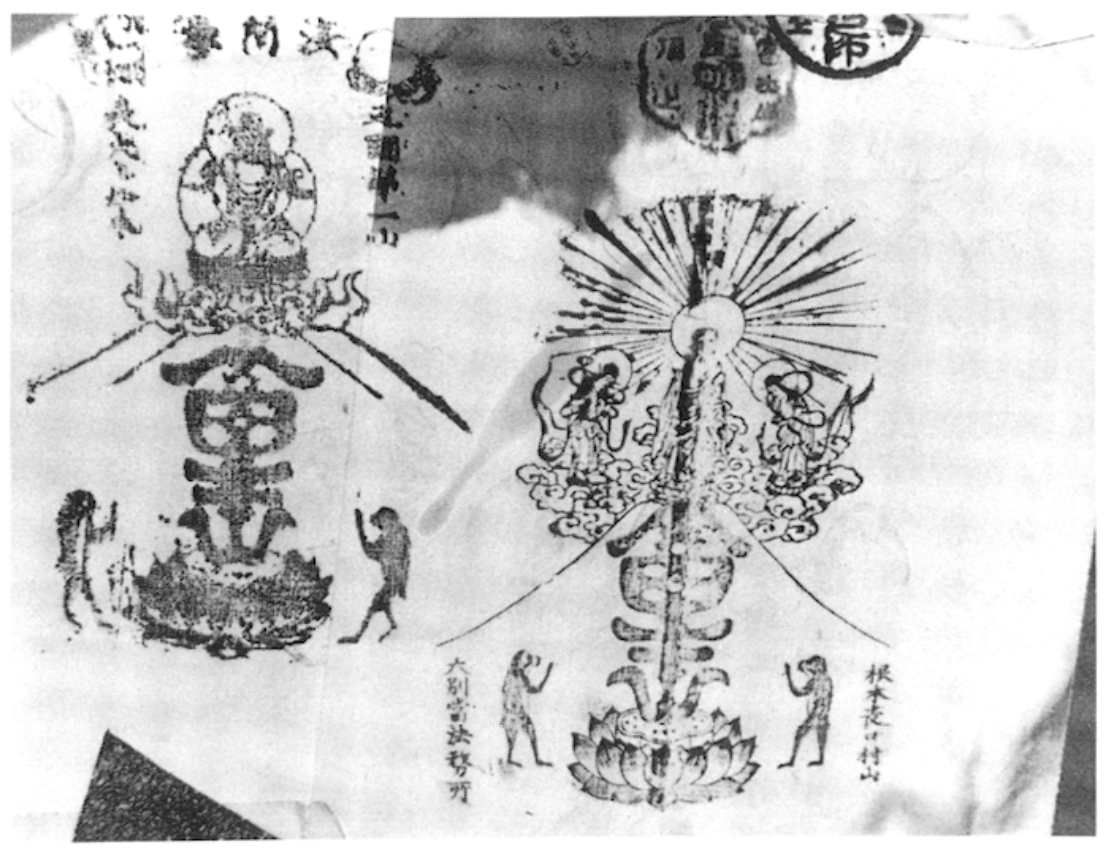

12 - Estampages sur la veste blanche des membres de la confrérie de Sengen de Tasō (Nanseichō). A gauche : Dainichi nyorai assis sur le lotus au-dessus du mont Fuji et entouré de l'inscription "Sengen (gü ?) (sanctuaire de) Sengen -, Sankoku dai issan - première montagne des trois pays -, Omote.guchi dainichi nyorai - Dainichi nyorai de l'entrée principale"; il domine les caractères verticaux de Fuji san sur le lotus entre les deux singes. A droite : la triade d'Amida est au-dessus de ces mêmes motifs et de l'inscription "Konpon omote.guchi Murayama - Entrée principale Murayama-", "Dai hettó hömushō - Bureau des affaires religieuses du grand bettōo". 


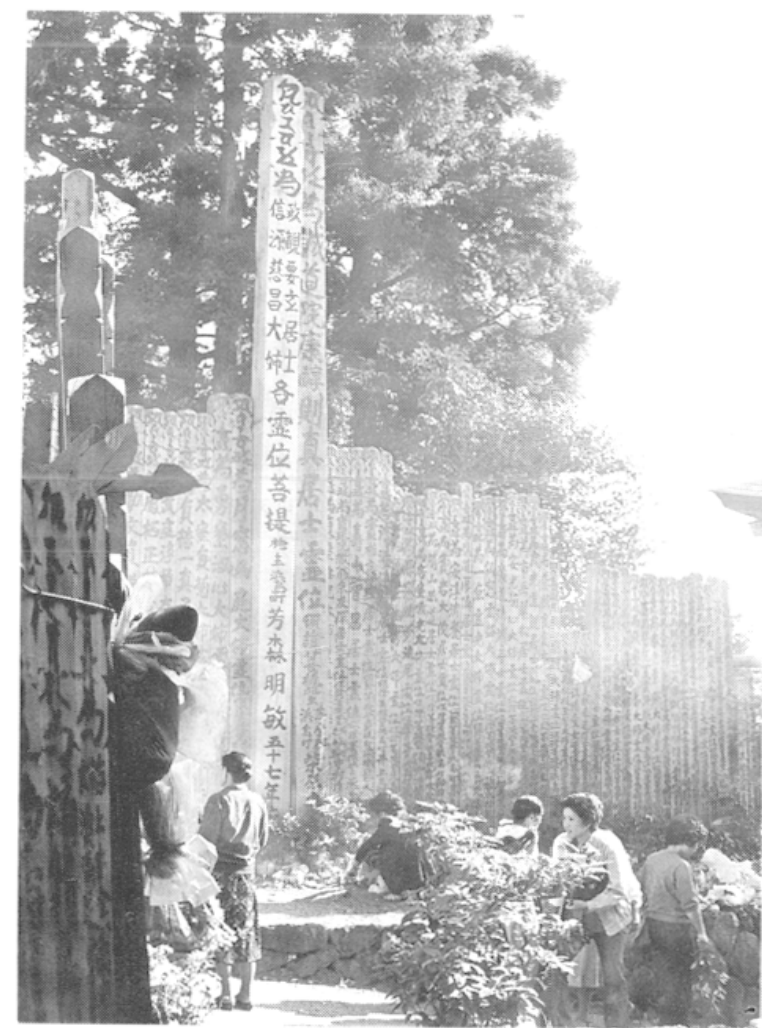

13 - Take mairi, le pèlerinage au mont Asama pour les âmes des morts, le 28 juin. Devant les grands töba dressés en commémoration des services accomplis pour le repos des âmes, les femmes déposent des offrandes d'encens, de nourriture et de feuillages. Au premier plan sur la gauche on aperçoit les vêtements d'un défunt accrochés à l'un des tôtha

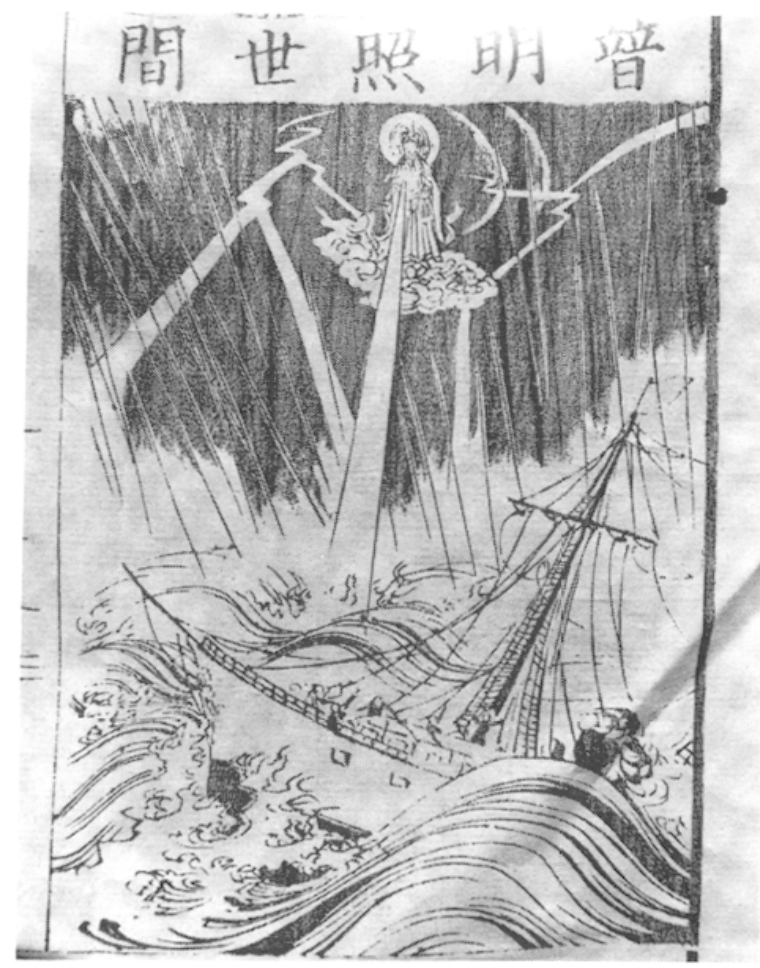

15 - Kannon du mont Aomine guidant de sa lumière surnaturelle un bateau dans la tempête (fragment d'une gravure représentant Kannon du mont Aomine et les diverses manifestations de ses pouvoirs protecteurs. Shōfukuji).

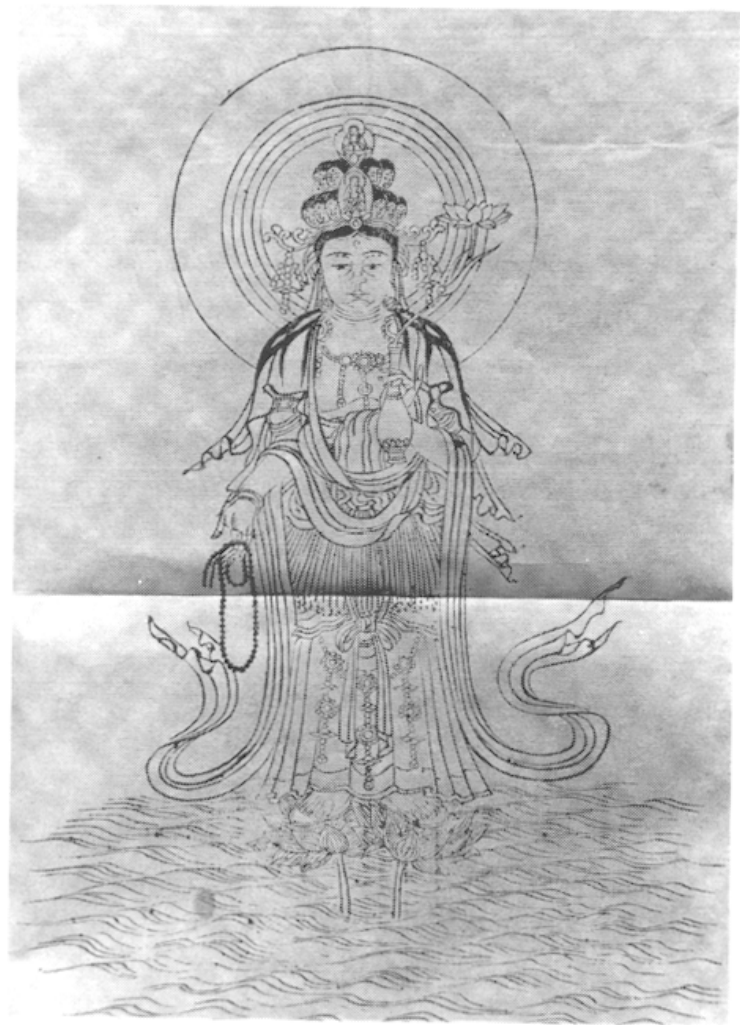

14 - Reproduction graphique de la statue de Kannon du Shōfukuji, temple du mont Aomine, debout sur un lotus sortant des flots de la mer et portant autour des reins le koshi mino (jupe de paille. vêtement porté autrefois en mer par les pêcheurs).

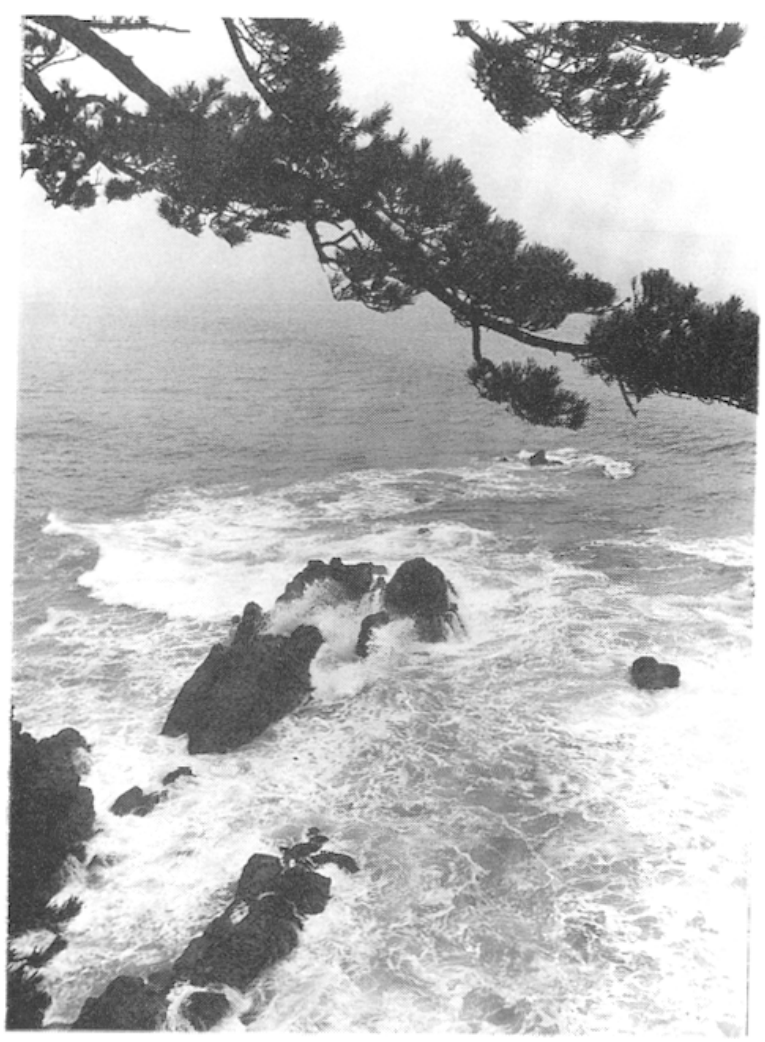

16 - Le "Rocher de la baleine" (Ōsatsu) considéré comme la métamorphose minérale de la baleine porteuse de la statue de Kannon. 


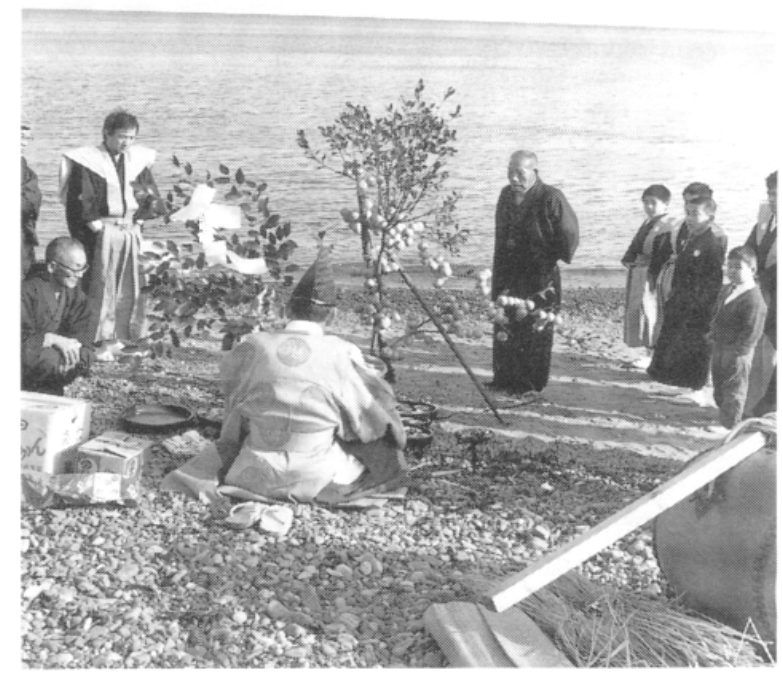

17 - Mitana shinji : 棚神少 - rite des trois tablettes -, Anori (Agochō), le ler janvier. Célébration des dieux de l'audelà de la mer à qui sont offerts une branche de mandarinier et des céréales en demande de protection et de bonne pêche pour l'annéc à venir.

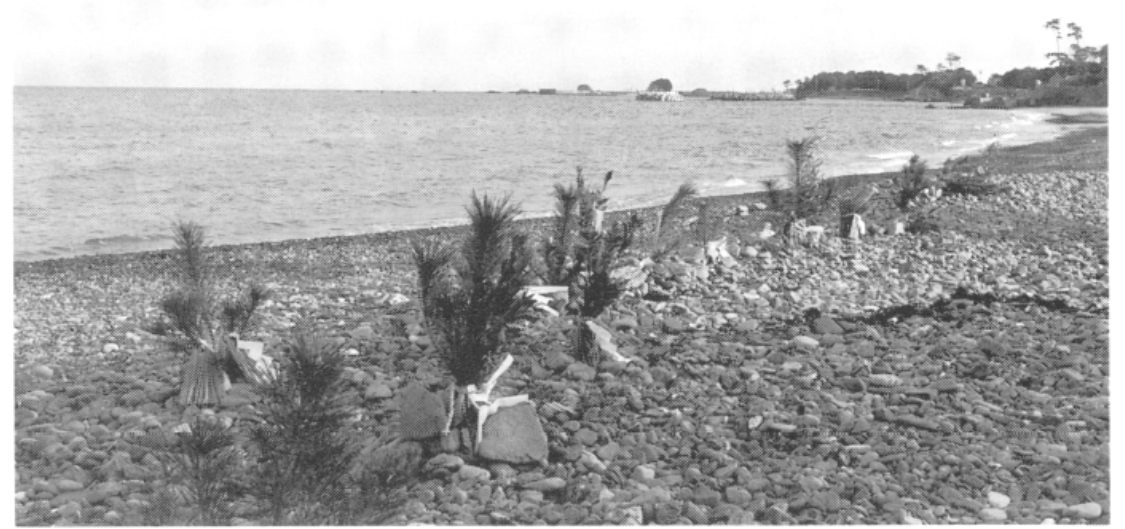

18 - Offrandes (branches de pin, riz dans un cône de paille) au "Palais du Dragon" déposées sur la plage pour le Nouvel An par les plongeuses et les pêcheurs (Köga, Agochō). 


\section{BIBLIOGRAPHIE DES OUVRAGES CITÉS}

Amino Yoshihiko 網野善彦

1994 Nihon shakai saikō-Kaimin to rettō bunka 日本社会再考・海民 と列島文化. Tōkyō: Shōgakkan 小学館.

1995 "Les Japonais et la mer" in L'histoire du Japon sous le regard japonais, Annales $50^{\mathrm{e}}$ année, $\mathrm{n}^{\circ}$ 2: 235-258. Paris : Armand Colin.

Amino Yoshihiko et al., éd. 網野善彦他編

1990-93 Umi to rettō bunka 海と列島文化. 11 volumes. Tōkyō : Shōgakkan.

Asamadake giki 朝熊岳儀軌

1979 in Shintō taikei, jinjahen 神道大系・神社編, vol. 14. Iga, Ise, Shima koku 伊賀・伊勢 - 志摩国 : 30-52. Tōkyō : Shintō taikei hensankai 神道大系編箱会.

Bouchy, Anne

1983a “Minzokuhen 民俗篇” in Kumano shishi 熊野市史, vol. III : 4511198. Kumano : Kumanoshi kyōiku iinkai 熊野市教育委員会.

1983b “Minkan shūkyō no shosō 民間宗教の諸相” in Kumano shishi, vol. III : 414-448. Kumano : Kumanoshi kyōiku iinkai.

1986 “Shima, Ise no Yakushi shinkō志摩・伊勢の薬師信仰” in Yakushi shinkō-Minshū shūkyōshi sōsho 薬師信仰/民衆宗教史 叢書, vol. $12:$ 123-185. Tōkyō : Yūzankaku 雄山閣.

1995 "Ama no nomi to umi no ryōshu no yumi - Ama shakai no rōdō keitai to sonraku soshiki no nijū kōzō - Mieken, Tobashi,

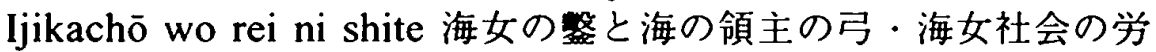
働形態と村落組織の二重構造・三重祡鳥羽市石鏡町を例にして” in Jendā no Nihonshi ジェンダーの日本史・下, vol. 2 : 389-430. Tōkyō : Tōkyō daigaku shuppan 東京大学出版.

Endō Hideo 遠藤秀男

1978 “Fuji shinkō no seiritsu to Murayama shugen 富士信仰の成立と 村山修験” in Fuji, Ontake to Chübu reizan - Sangaku shūkyōshi kenkyū sōsho 富士・御获と中部霊山/山岳宗教史研 究叢書, vol. 9 : 26-57. Tōkyō : Meicho shuppan 名著出版.

Frank, Bernard

1991 Le panthéon bouddhique au Japon - Collections d'Emile Guimet. Paris : Réunion des Musées nationaux.

Fuji no hitoana sōshi 富士の人あなさうし

1938 in Muromachi jidai monogatari shu 室町時代物語集, vol. II: 338355, sous la dir. de Yokoyama Shigeru 横山重. Tōkyō: Ōokayama shoten 大岡山書店. 
Fujisan no ki 富士山記

in Gunsho ruijū 群書類從, vol. 9 : 318-319. 1977 (rééd.). Tōkyō :

Zoku gunsho ruijū kanseikai 續群書類從完成會.

Gorai Shigeru 五来重

1975 “Kumano sanzan no rekishi to shinkō 熊野三山の歴史と信仰” in Yoshino, Kumano shinkō no kenkyū - Sangaku shūkyōshi kenkyū sōsho 吉野・熊野信仰の研究/山耍宗教史研究叢書, vol. 4 : 155178. Tōkyō : Meicho shuppan.

1980 Shugendō nyūmon 修験道人門. Tōkyō: Kadokawa shoten 角川書 店.

1983 “Jofuku densetsu 徐福伝説” in Kumano shishi, vol. 1 : 350-364. Kumano : Kumanoshi kyōiku iinkai.

1989 Yugyō to junrei 遊行と巡礼. Kadokawa sensho 角川選書 192. Tōkyō : Kadokawa shoten.

1995 Shugendō no rekishi to tabi-Shūkyō minzoku shūsei 修驗道の歴 史の旅 - 宗教民俗集成, vol. 1. Tōkyō: Kadokawa shoten.

Honchō seiki 本朝世記

in Shintei zōho kokushi taikei 新訂增補国史大系, 1966 (rééd.).

Tōkyō : Yoshikawa kōbunkan 占川弘文館.

Inobe Shigeo 井野辺茂雄

1928a Fuji no rekishi 富士口歴史. Tōkyō: Kokin shoin 吉今書院.

1928b Fuji no shinkō 富士の信仰. Tōkyō: Kokin shoin.

Ise Asamadake ryaku engi 伊勢朝熊岳略縁起

1984 in Shugendō shiryōshū 修驗道資料集, vol. 2 - Sangaku shūkyōshi

kenkyü sōsho 中部霊山/山岳宗教史研究叢書, vol. 18 : 108-110, 745-746. Tōkyō : Meicho shuppan.

Itō Abito 伊藤严人

1983 “Gyomin shūdan to sono katsudō 漁民篗団とその活動” in Sanmin to ama - Nihon minzoku bunka taikei 山民と海士／日本 民俗文化大采, vol. 5 : 319-362. Tōkyō : Shōgakkan.

Iwashina Koichirō 岩科小一郎

1978 “Sōseiki no Fujikō - Kakugyō to Miroku 創成期の富士講 - 角 行と身称” in Fuji, Ontake to Chübu reizan - Sangaku shūkyōshi kenkyū sōsho 富士・御获と中部霊山/山岳宗教史研 究叢書, vol. 9 : 58-75. Tōkyō : Meicho shuppan.

1983 Fujikō no rekishi, Edo shomin no sangaku shinkō 富士講の歴史／ 江宁庶民の山岳信仰. Tōkyō : Meicho shuppan.

Kawaoka Takeharu 河岡武春

1983 “Kuroshio no ama 黑潮の海人” in Sanmin to ama - Nihon minzoku bunka taikei 山民と海人／日本民俗文化大系，vol. 5 : 363-393. Tōkyō : Shōgakkan. 
Miyamoto Tsuneichi 宮本常-

1976 “Minzoku no chiikisei 民俗の地域性” in Minzokugaku taikei 民俗 学大系, vol. 2 : 67-80. (rééd. de 1958) Tōkyō : Heibonsha 平凡社

1995 Umi ni ikiru hitobito 海に生きる人々. Nihon minshüshi 日本民衆 史, vol. 3. (rééd. de 1964) Tōkyō : Miraisha 未来社.

Miyata Noboru 宮田登

1965 “Asama shinkō アサマ信仰” in Shima no minzoku 志摩の民俗： 308-321. Tōkyō : Yoshikawa Kōbunkan 吉川弘文館.

Noguchi Takenori 野口武徳

1983 “Funadama to Ebisu 船霊とエビス” in Sanmin to ama - Nihon minzoku bunka taikei 山民と海人／日本民俗文化大系, vol. 5： 394-420. Tōkyō : Shōgakkan.

Ōmori Yoshinori 大森義憲

1978 “Fuji no oshi 富士の御師” in Fuji, Ontake to Chübu reizan Sangaku shūkyōshi kenkyū sōsho 富士・御孰と中部霊山/山岳宗 教史研究叢書, vol. 9 : 76-96. Tōkyō : Meicho shuppan.

Origuchi Shinobu 折口信夫

1975 “Kokubungaku no hassei (dai san kō) marebito no igi 国文学の 発生 (第三稿)まれびとの意義” in Kodai kenkyū, Kokubungaku hen 古代研究・国文学篇, Origuchi Shinobu zenshū 折口信夫全 集, vol. 1. Tōkyō : Chūkō bunko 中公文庫.

1975 “Hahaga kunihe, tokoyohe 妣が国へ、常世へ”：3-15, “Kodai seikatsu no kenkyū 古代生活の研究”: 42-79, “Ryūkyū no shūkyō 琉球の宗教”: 16-41, in Kodai kenkyū, Minzokugaku hen, Origuchi Shinobu zenshū, vol. 2. Tōkyō : Chūkō bunko.

Pigeot, Jacqueline.

1993 Voyages en d'autres mondes, Récits japonais du XVI siècle. Paris : Editions Philippe Picquier/Bibliothèque Nationale.

Sakurada Katsunori 桜田勝徳

1976 “Gyogyō 漁業” in Minzokugaku taikei 民俗学大系, vol. 5：75119. (rééd. de 1959) Tōkyō : Heibonsha.

Shokoku zue nenjūgyōji taisei 諸国図会年中行事大成

1978 Tōkyō : Girei bunka kenkyūsho 儀礼文化研究所.

Yanagida Kunio 柳田国男

1978 “Kaijō no michi 海上の道” in Teihon Yanagida Kunio zenshū 定 本柳田国男全集, vol. 1 : 1-216. (rééd. de 1968) Tōkyō: Chikuma shobō 筑攀書房. 